\title{
Schluß und Ausblick
}

Ist der Fluchtpunkt der deutsch-tschechoslowakischen Beziehungen der Zwischenkriegszeit auch zwangsläufig „München“, so war dieses tragische Ende doch nicht unausweichlich; die Sichtweise vom Ende her blendet kontrafaktische Entwicklungspfade aus. Zwar herrschte grundsätzlich wenig Begeisterung auf der tschechischen Seite über die Anwesenheit einer zahlenmäßig starken, ökonomisch potenten deutschen Volksgruppe im Lande, ohne deren Siedlungsgebiete der Staat nicht lebensfähig erschien. Jenseits des Grundkonsenses, daß die Tschechoslowakei der Nationalstaat der Tschechen und Slowaken sei und den Deutschen die Position einer Minderheit zukomme, existierte aber kein verbindliches Konzept, keine „Staatsdoktrin“ für den Umgang mit ihnen. In der vielschichtigen, in vielerlei Hinsicht bislang übrigens nur ungenügend erforschten Realität des tschechisch-deutschen Verhältnisses in der Zwischenkriegszeit mischten sich denn auch Konflikt und Kooperation reich facettiert. Daß soziale, wirtschaftliche und politische Beziehungen zwischen verschiedenen ethnischen Gruppen nie reine Konfliktbeziehungen sind, daß sie als ausschließlich konfliktuös nicht einmal denkbar sind, ist eine an sich einfache Wahrheit, die aber beileibe noch nicht überall das Bild der Ersten Republik in Forschung und Öffentlichkeit bestimmt.

Speziell auf dem Terrain der Wirtschaft wurde das Verhältnis zwischen Deutschen und Tschechen in der Ersten Republik zwar beidseits durch ein aggressives Streben nach Erweiterung nationaler Besitzstände, durch Chauvinismus und einen - zumindest aus der zeitlichen und emotionalen Distanz des nachgeborenen Betrachters - offensichtlichen Schuß Paranoia beeinträchtigt. Ungeachtet dessen bestätigte sich der Anfangsverdacht der Einleitung: Die Praktiker der Wirtschaft und in ihrer Folge die Wirtschaftspolitik zogen im allgemeinen doch eine Konzertierung "objektiver“ gemeinsamer oder paralleler Interessen und die Ausschöpfung von Synergien der Konfrontation vor. Regellose Verdrängungskämpfe zwischen Tschechen und Deutschen begegnen nur punktuell, etwa in Gestalt der „Säuberung“ deutscher Angestellter in der „unordentlichen “ allerersten Nachkriegszeit oder im Zuge der Quasi-Machtergreifung durch die SdP im teilweise bereits chaotischen Vorfeld von München. Normale Zeiten hingegen waren durch relativ stabile, mehr oder weniger explizite, in freier Vereinbarung paktierte (im Fall der Industrieverbände) oder staatlich gesatzte (Kammern, Arbeitsmarkt) Regelungen von Ansprüchen und Handlungsspielräumen, Eigentums- und Verfügungsrechten charakterisiert. Diese garantierten vermutlich nicht in jedem Fall dem deutschen Element einen „fairen Anteil“ (was auch immer hierunter zu verstehen wäre), zielten ersichtlich aber auch nicht auf Aufsaugung und Verdrängung. Ein erster Regulierungsund Institutionalisierungsschub datiert aus den Anfangsjahren der Republik: die Umschichtung der Verwaltungskommissionen der Kammern von 1918/19, die erste Kooperation der Industrieverbände im Zentralausschuß von 1922 und die Arbeitsmarktregelung von 1923. Die „Novellierungen“ der späteren zwanziger Jahre - Umschichtung der Verwaltungskommissionen 1926/27, Zusammenschluß der Industrieverbände 1928, Arbeitsmarktregelung von 1928 - beeinträchtigten den Status quo nicht wesentlich. In den dreißiger Jahren verschärfte sich die Konfrontation. Aber sogar das Staatsverteidigungsgesetz, das den Kulminationspunkt der Konfrontation markieren dürfte, erodierte keineswegs die Position der Deutschen in der Wirtschaft der Republik. 
In den zusammenfassenden Abschnitten zu den drei Fallstudien sind bereits die jeweils wirksamen ökonomischen, organisatorischen, rechtlichen, innen- und außenpolitischen Rahmenbedingungen, die Beweggründe der Akteure und die hieraus resultierende "spezifische Mischung" von Konflikt und Kooperation dargestellt worden. Abschließend bleibt die Aufgabe, Kräfte und Konstellationen, die „objektiven“, von der Sympathie, dem guten Willen oder auch Übelwollen Einzelner unabhängigen Determinanten noch einmal im Überblick zu benennen.

1. Mag „die tschechische Politik“ im Grundsatz auch von mehr oder zuzeiten auch weniger unfreundlichen Gefühlen gegenüber „den Deutschen“ grundiert gewesen sein, so wurde diese unzweifelhaft vorhandene Disposition doch nicht in ein umfassendes und konsistentes antideutsches Politikprogramm übersetzt. Die von der deutschen Volkstumskampfrhetorik mancherorts behauptete Existenz eines „Master Plan“ entbehrt der Grundlage - ebendies gilt übrigens für die tschechischen Verschwörungstheorien. Zielsysteme der Parteien wie Beweggründe einzelner Akteure waren hierfür zu vieldimensional und komplex. Am ehesten als „eindimensional“, ja sogar als stereotyp dürften Programmatik und Aktivitäten des Nationalrats und der Volkstumsvereine zu bewerten sein. Die faktische und moralische, auf dem Wege über personelle Enflüsse, oft informell, hinter den Kulissen wirksam werdende Interventions- und Pressionsmacht des Nationalrats darf zwar nicht unterschätzt werden; sie höhlte stetig und lautlos den Stein, bestimmte, wie an vielen Stellen dieser Untersuchung deutlich wird, die tschechische Politik aber keineswegs ausschließlich. In längerfristiger Betrachtung erlebten nationalistische Tendenzen in der Wirtschaft auf beiden Seiten Hausse und Baisse, manchmal, aber nicht immer synchron zur Entwicklung der deutsch-tschechischen politischen Beziehungen. Häufig zu beobachten war die populistische Instrumentalisierung der "nationalen Karte“, etwa in Wahlkämpfen. Ankündigungen und reale Aktivitäten sind durchwegs sorgfältig auseinanderzuhalten.

2. Von erstrangiger Bedeutung sind in diesem Zusammenhang die für eine entwickelte Industriegesellschaft charakteristischen Eigengesetzlichkeiten rationaler Ökonomie bzw. funktionaler Organisation. Diese Sacherfordernisse setzten sich auf dem Terrain der Wirtschaft weitgehend durch - weitergehend vermutlich als in anderen, eher ,ideologieanfälligen“ Sphären des Zusammenlebens; nationalpolitische Bruchlinien wurden durch übernationale Interessen-, Aktions- und Profitgemeinschaften überwölbt. Der entscheidende Beweggrund war - nicht verwunderlich - taktisches Kalkül; Zusammenarbeit war nicht bzw. nicht zwangsläufig Herzensangelegenheit. Die ungenaue, ja sogar irreführende, trotzdem unumgängliche Rede von einer „deutschen“ und einer „tschechischen Wirtschaft“ verdeckt leicht den Umstand, daß es sich hierbei nicht um autonome, separate oder überhaupt separierbare Wirtschaftskörper handelte; beide waren durch Abhängigkeitsbeziehungen wechselseitig, geradezu auf Gedeih und Verderb verbunden. Die List der Vernunft in der Gestalt tschechischer Kapitalbeteiligungen an deutschen Unternehmen etwa schmälerte das Interesse an einer „Tschechisierung“ der Belegschaften und an einer Entfernung deutscher Experten und Manager zumindest dort, wo die Funktionsfähigkeit der Betriebe beeinträchtigt worden wäre. Im Verbandswesen wirkte die Sacherfordernis, die Schlagkraft der industriellen Interessenvertretung zu verbessern, als Motor der Zusammenarbeit. 
3. Der Nationalitätenkonflikt spielte sich in der Ersten Republik im Rahmen einer - immerhin! - leidlich funktionierenden Demokratie ab. Die aktivistischen deutschen Parteien nahmen ab der zweiten Hälfte der zwanziger Jahre am politischen Prozeß teil. Auch wenn die Reichweite ihres Einflusses kontrovers ist und nicht überschätzt werden sollte, so ist doch die Annahme plausibel, daß sie über eine gewisse Verhandlungs- und Vetomacht verfügten. Eine wichtige Rolle spielte auch - trotz aller Mängel der Praxis das Ensemble inner- und zwischenstaatlicher Rechtsnormen, denen die Republik in ihrem Verständnis als Rechtsstaat unterworfen war bzw. durch die sie sich mehr oder weniger freiwillig gebunden hatte. Auch „unfreundliche“ Maßnahmen hielten sich, ungeachtet aller in der Praxis zu beobachtenden Defizite, deshalb weitgehend in dem vom Recht vorgegebenen Rahmen. Nicht immer, aber in der Regel verhinderte eine funktionierende Rechtsprechung - am deutlichsten zu beobachten in Arbeitsmarkt- und Staatsbürgerschaftsfragen - Übergriffe der Behörden in die Privatwirtschaft. Richtschnur war insbesondere Artikel 106 der Verfassung, der u. a. allen Einwohnern der ČSR den Schutz von Leben und Freiheit ohne Rücksicht auf die Staatsangehörigkeit garantierte und Abweichungen hiervon nur nach Maßgabe des im Völkerrecht Erlaubten für zulässig erklärte. Hierher gehörten weiterhin der Grundsatz der Berufs- und der Gewerbe-, der Vertrags- und der Koalitionsfreiheit, nicht zuletzt auch die Minderheitenschutzbestimmungen der Verträge von St. Germain bzw. von Versailles. Ungeachtet zahlreicher, sicherlich nicht unberechtigter Klagen über die Verletzung dieser Normen wirkten sie als eine gewisse Schranke gegen Willkür. Nicht zu unterschätzen ist auch die Rolle Deutschlands bzw. Deutschösterreichs als Protektoren der Deutschen in der Tschechoslowakei.

4. Bestätigt hat sich insbesondere auch die Eingangsvermutung, daß nicht alle auf den ersten Blick antideutsch wirkenden Maßnahmen als solche intendiert waren. „Diskriminierung“ und „Verdrängung“ der Deutschen waren in vielen Fällen tatsächlich Resultat struktureller Defizite des ökonomischen oder politischen Systems oder Folge ungünstiger kontingenter Umstände und Ereignisse. Die als Grundzug von Wirtschaft und Gesellschaft der Ersten Republik konstatierte generelle Schwäche des intermediären Systems hat sich in dieser Untersuchung für den Fall der Industrieverbände bestätigen lassen. Die aus deutscher Sicht oft beklagte Einflußlosigkeit des Hauptverbands war zu einem guten Teil die Einflußlosigkeit der Verbände generell, nicht die der Deutschen im besonderen. Die Schmälerung der deutschen Position in den Kammern hängt ebenfalls mit den Eigenheiten der „versäulten Demokratie“ zusammen; Proportionalisierung und Interessenausgleich via Paktierung führten zu den im Zusammenhang mit der Vergabe der Kammermandate beschriebenen Erscheinungen. Versäulung war zum Beispiel auch verantwortlich dafür, daß alle Anläufe zu einer Kammerreform über zwei Jahrzehnte hinweg ergebnislos blieben. Hierdurch und nicht durch antideutsche Ranküne wurden die Wahlen verhindert, die vermutlich den Deutschen einen prominenteren Platz in den Kammern gesichert hätten. Die Unbeweglichkeit der Politik und der Schlendrian einer manchmal behäbig bis sklerotisch anmutenden Bürokratie verhinderten in den dreißiger Jahren eine durchgreifende Antikrisenpolitik; diese Strukturzüge, nicht tschechischer „Vernichtungswille“ waren für die oft beschriebene Misere und den Niedergang der deutschen Exportwirtschaft verantwortlich, die sich auf der Verbandsebene in der "Juniorpartnerschaft" des Hauptverbands zum Zentralverband oder 
etwa in der finanziellen Abhängigkeit des DHI-Präsidenten Liebieg vom tschechischen Finanzkapital reflektierte. Auf der anderen Seite sollte aber auch in Rechnung gestellt werden, daß gerade die oft konstatierte und beklagte Verkrustung der politischen Strukturen der Ersten Republik auf dem Feld der Nationalitätenpolitik radikale Maßnahmen verhinderte.

In dieser Studie konnten lediglich einige Stichproben zu den tschechisch-deutschen Wirtschaftsbeziehungen vorgelegt werden; das in erster Annäherung umrissene, dann grob vermessene Forschungsfeld weist derzeit noch weitaus mehr weiße Flecken als Parzellen gesicherten Wissens auf. Wichtige Akteure und Segmente der Wirtschaft der Ersten Republik und ihres Zusammenspiels mit der Politik, die dort jeweils charakteristischen Gemengelagen von Konflikt und Kooperation zwischen Deutschen und Tschechen und die konkreten Abläufe und Entwicklungen sind noch nicht oder nur völlig ungenügend untersucht. Schon auf dem Feld der Industrieverbände wäre das noch sehr grobkörnige Bild zu differenzieren - z. B. zeitlich und nach Branchen. Eine weitere schmerzliche Lücke, die in dieser Studie nicht zu schließen war, ist die Nationalitätenproblematik auf der Ebene der Arbeiterschaft und ihrer Organisationen. Unbefriedigend ist der aktuelle Kenntnisstand zum Beispiel auch, was das Handwerk und den Handel und ihre Organisationen anbetrifft. ${ }^{1}$ Eine Erweiterung des Wissens wäre nicht zuletzt von lokalen bzw. regionalen Mikrostudien der deutsch-tschechischen Interaktion in der Wirtschaft zu erwarten.

Die Befunde sind also partiell; dementsprechend vorläufig sind die Schlußfolgerungen. $\mathrm{Zu}$ hoffen bleibt, daß die Forschung auf der Grundlage der seit einigen Jahren in der Tschechischen Republik zugänglichen umfangreichen Quellenbestände verstärkt die Schließung dieser Lücken in Angriff nimmt. In einem zweiten Schritt wären die Resultate auf dem Terrain "Nationalität und Wirtschaft" mit denen auf anderen Feldern der Nationalitätenproblematik, etwa in der Sprachen-, der Schul- und der Staatsangestelltenproblematik, abzugleichen und in systematisierender Absicht, im Hinblick auf ein möglichst vollständiges Gesamtbild nach den je spezifischen Mischungen von Kooperation und Konflikt, von Emotion und Kalkül, den je charakteristischen Regelungsmechanismen und ihren ökonomischen und sozialen Kosten abzufragen. ${ }^{2}$ Nicht zuletzt ist die Einordnung der tschechoslowakischen Befunde in eine international vergleichende Perspektive ein Desiderat. ${ }^{3}$

1 Zum Bankwesen und seinen Verbänden bereitet Eduard Kubů von der Prager Karls-Universität eine umfangreiche Untersuchung vor; den ersten Informationen zufolge wird sie den hiesigen Befund einer vergleichsweise niedrigen Konfliktintensität in der Wirtschaft im wesentlichen bestätigen.

2 Die wichtigste Referenzgröße ist die Studie meines Kollegen Jaroslav Kučera über die Sprachenfrage in der Ersten Republik. Der Brückenschlag zwischen beiden Themen in der Form einer längeren Abhandlung ist in Aussicht genommen.

3 Alice Teichova und Herbert Matis haben auf einer Konferenz in Wien im Juni 1997 einschlägige Beiträge von Finnland über Belgien bis Spanien und Griechenland versammelt. 


\section{Quellen}

\section{Archivalische Quellen}

ARCHIV KANCELÁŘE PREZIDENTA REPUBLIKY, PRAG

(Archiv der Kanzlei des Präsidenten der Republik)

Bestand „D“ (Dủležité/Wichtig)

Bestand „T“ (Tajné/Geheim)

ARCHIV MINISTERSTVA ZAHRANIČNICH VĚCf, PRAG

(Archiv des Außenministeriums)

Sektion I (Kabinett des Ministers)

Sektion II (Politische Abteilung)

Sektion III (Berichterstattung)

Sektion IV (Wirtschaftsabteilung)

ARCHIV NÁRODNÍ BANKY, PRAG

(Archiv der Nationalbank)

(HEUTE: ARCHIV ČESKÉ NÁRODNÍ BANKY)

(Archiv der Tschechischen Nationalbank)

Živnostenská banka (Gewerbebank), Privatkorrespondenz Preiss

Živnostenská banka (Gewerbebank), Protokolle des Exekutivausschusses

Agrarní banka (Agrarbank)

ARCHIV NÁRODNÍHO MUZEA, PRAG

(Archiv des Nationalmuseums)

NL Hodža

NL Rašín

\section{ARCHIV PARLAMENTU ČESKÉ REPUBLIKY}

(Archiv des Parlaments der Tschechischen Republik)

Protokolle der Sitzungen des gewerbe- und handelspolitischen Ausschusses

Protokolle der Sitzungen des sozialpolitischen Ausschusses

\section{STÁTNI ÚSTŘEDNI ARCHIV, PRAG}

(Staatliches Zentralarchiv)

Ministerstvo financí

(Ministerium der Finanzen)

Ministerstvo průmyslu, obchodu a živností

(Ministerium für Industrie, Handel und Gewerbe)

Ministerstvo průmyslu, obchodu a živností, dodatky 
(Ministerium für Industrie, Handel und Gewerbe, Zusätze)

Ministerstvo sociální péče

(Ministerium für soziale Fürsorge)

Ministerstvo veřejných prací

(Ministerium für öffentliche Arbeiten)

Ministerstvo vnitra

(Ministerium des Innern)

Národní rada československá

(Tschechoslowakischer Nationalrat)

NL Hodáč

Předsednictvo ministerské rady

(Präsidium des Ministerrats)

Státní úřad statistický

(Statistisches Staatsamt)

Sudetendeutsche Partei

Sudetendeutsche Partei, dodatky

(Sudetendeutsche Partei, Zusätze)

Ústřední svaz československých průmyslníků

(Zentralverband der tschechoslowakischen Industriellen)

Ústředna obchodních a živnostenských komor

(Zentrale der Handels- und Gewerbekammern)

VOJENSKÝ HISTORICKÝ ARCHIV, PRAG

(Militärhistorisches Archiv)

Ministerstvo národní obrany/Hlavní štáb

(Ministerium für nationale Verteidigung/Generalstab)

Vojenská kancelář prezidenta republiky

(Militärkanzlei des Präsidenten der Republik)

POLITISCHES ARCHIV DES AUSWÄRTIGEN AMTES, BONN

Politische Abteilung II b

Handelspolitische Abteilung IV a

Gesandtschaft Prag

BUNDESARCHIV, ABTEILUNG KOBLENZ

Reichskanzlei

Reichswirtschaftsministerium

BUNDESARCHIV, ABTEILUNG BERLIN

Auswärtiges Amt

Reichswirtschaftsministerium 


\section{SÄCHSISCHES HAUPTSTAATSARCHIV, DRESDEN}

Sächsische Gesandtschaft Berlin

Sächsisches Ministerium der Auswärtigen Angelegenheiten

ZENTRALES STAATSARCHIV, MERSEBURG

Preußisches Ministerium für Handel und Gewerbe

\section{BAYERISCHES HAUPTSTAATSARCHIV, MÜNCHEN}

Bayerische Staatskanzlei

Bayerisches Staatsministerium des Äußern, für Wirtschaft und Arbeit

IHK-WIRTSCHAFTSARCHIV FÜR MÜNCHEN - OBERBAYERN, MÜNCHEN

Industrie- und Handelskammer München-Oberbayern

Bayerischer Industrie- und Handelstag

INSTITUT FÜR ZEITGESCHICHTE, MÜNCHEN

Nürnberger Dokumente

ARCHIV DES VÖLKERBUNDES, GENF (FONDATION ARCHIVES EUROPÉENNES)

Fonds du sécrétariat, section des commissions administratives et des questions de minorités

ÖSTERREICHISCHES STAATSARCHIV - ARCHIV DER REPUBLIK, WIEN

Bundesministerium für Auswärtige Angelegenheiten, Gesandtschaft Prag 


\section{Gedruckte Quellen und Dokumentensammlungen, Kompendien und Nachschlagwerke}

Akten zur Deutschen Auswärtigen Politik, Serien A, B, C, D.

Balling, Mads Ole, Von Reval bis Bukarest. Statistisch-biographisches Handbuch der Parlamentarier der deutschen Minderheiten in Ostmittel- und Südosteuropa 19191945, Band 1, Kopenhagen 1991.

Berichte des Verbandes mährischer Industrieller in Brünn, $1920 \mathrm{ff}$.

Berichte des Vereines der Wollindustriellen Mährens in Brünn, $1920 \mathrm{ff}$.

Biographisches Lexikon zur Geschichte der böhmischen Länder, hrsg. im Auftrag des Collegium Carolinum von Heribert Sturm, Band 1-3, München 1979-1989.

Compass (Tschechoslowakei). Finanzielles Jahrbuch.

Československé dějiny v datech, Praha 1992.

Deutscher Hauptverband der Industrie, Tätigkeitsberichte.

Deutsche Gesandtschaftsberichte aus Prag. Innenpolitik und Minderheitenprobleme in der Ersten Tschechoslowakischen Republik: Teil I, Von der Staatsgründung bis zum ersten Kabinett Beneš (1918-1921), bearbeitet von Manfred Alexander, München/ Wien 1983. - Teil IV, Vom Vorabend der Machtergreifung in Deutschland bis zum Rücktritt von Masaryk (1933-1935), bearbeitet von Heidrun und Stephan Dolezel, München 1991.

Encyklopedický institut ČSAV (Hrsg.), Československý biografický slovník, Praha 1992.

Foreign Relations of the United States, Paris Peace Conference, 1919, Bände III, XII.

Der Friedensvertrag zwischen Deutschland und den alliierten und assoziierten Mächten: amtlicher Text der Entente und amtliche deutsche Übertragung, Charlottenburg 1919.

Die Gesetzesanträge der Sudetendeutschen Partei, o.V., Karlsbad-Leipzig 1937.

Handbuch der Geschichte der böhmischen Länder.

Jahresberichte der Deutschpolitischen Arbeitsstelle.

Národní shromáždění Československé v prvním roce republiky, Praha 1919.

Národní shromáždění republiky Československé v prvém desítiletí, Praha 1928.

Národní shromáždění republiky Československé v druhém desítiletí, Praha 1938.

Protokolle des Bayerischen Landtags.

Protokolle des Reichstags.

$\mathrm{Z}$ protokolů schůzí 6. československé vlády (1. Švehlovy), 7. říjen 1922 - 9. prosince 1925.

Raschhofer, Hermann (Hrsg.), Die tschechoslowakischen Denkschriften für die Friedenskonferenz von Paris 1919/1920, Berlin 1937.

Reichsgesetzblatt.

Reichsarbeitsblatt.

Reichshandbuch der deutschen Gesellschaft, Band 2, Berlin 1931.

Sbírka zákonů a nařízení státu československého.

SOPADE. 
Stanovy jednoty průmyslníků v Praze a okolí. Odbor svazu rakouských průmyslníků, Prag 1903.

Die SdP im Parlament. Ein Jahresbericht 1935/36, Karlsbad-Leipzig 1937.

Tisky $\mathrm{k}$ těsnopiseckým zprávám Poslanecké sněmovny (Drucksachen zu den stenografischen Berichten des Abgeordnetenhauses).

Tisky $\mathrm{k}$ těsnopiseckým zprávám Revolučního národního shromáždění (Drucksachen zu den stenografischen Berichten der Revolutionären Nationalversammlung).

Tisky $\mathrm{k}$ těsnopiseckým zprávám Senátu (Drucksachen zu den stenografischen Berichten des Senats).

Tẽsnopisecké zprávy Revolučního národního shromáždění (Stenografische Berichte der Revolutionären Nationalversammlung).

Těsnopisecké zprávy Poslanecké sněmovny (Stenografische Berichte des Abgeordnetenhauses).

Tẽsnopisecké zprávy Senátu (Stenografische Berichte des Senats).

Ursachen und Folgen. Vom deutschen Zusammenbruch 1918 und 1945 bis zur staatlichen Neuordnung Deutschlands in der Gegenwart.

Verordnungsblatt für die sudetendeutschen Gebiete. 


\section{Literatur}

\section{Zeitgenössische Literatur}

„A.B.“, Ein neues Handelskammergesetz, in: WI 9 (1928), S. $1091 \mathrm{f}$.

ADAMOVICH, Ludwig, Grundriß des Tschechoslowakischen Staatsrechtes, Wien 1929.

Der AGRARISCHE Zug, in: WI 10 (1928), S. $523 \mathrm{f}$.

ARBEIT für 300000 . Schutz der Arbeitslosen vor ärgster Not. Ein Sofortprogramm der SHF, Karlsbad 1935.

ARBEITSWISSENSCHAFTLICHES INSTITUT DER DEUTSCHEN ARBEITSFRONT (HRSG.), Das Sudetendeutschtum. Seine wirtschaftlichen, sozialen und geschichtlichen Grundlagen, Berlin 1938.

ARENS, Franz, Die wirtschaftliche Machtstellung des Deutschtums im tschechoslowakischen Staate, in: Zeitschrift für Politik 19 (1930), S. 676-689.

DERS., Die nationalwirtschaftlichen Umschichtungen der Nachkriegszeit im westlichen und südlichen Böhmen, in: Volk und Reich 8 (1932), 2. Beiheft: Süddeutsche Ostnot, S. 77-86.

DERS., Die wirtschaftliche Einflußsphäre des Deutschtums in den Sudetenländern seit Begründung des tschechoslowakischen Staates, in: Preussische Jahrbücher 1933, S. 156-167.

„ARGUS“, Kriegsanleihe und Industrie, in: OB 2 (1920), Nr. 27, S. 1 f.

$\mathrm{BACH}$, Theodor, Die politische Vertretung der Industrie. Eine Erweiterung, in: MDHI 2 (1921), S. 399-401.

BACHER, Franz, Der Hauptverband der Industrie, in: WI 1 (1919), S. 1.

DERS., Die Senatswahlen und die Wirtschaft, in: WI 2 (1920), S. 1.

DERS., Eine abtretende Regierung, in: WI 2 (1920), S. 227.

DERS., Eine neue Regierung, in: WI 3 (1921), S. 257.

DERS., Deutsch-tschechische Verhandlungen, in: WI 8 (1926), S. 403.

DERS., Eine neue Regierung, in: WI 8 (1926), S. $975 \mathrm{f}$.

DERS., Die Idiosynkrasie gegen den Fachmann, in: WI 10 (1928), S. 931.

DERS., Der Zusammenschluß des Hauptverbandes mit dem SVAZ, in: WI 10 (1928), S. $1135 \mathrm{f}$.

DERS., „... und den Fremden, der in Deinen Toren weilt“, in: WI 10 (1928), S. $1283 \mathrm{f}$.

DERS., („F.B.“), Konstruktive, nicht destruktive Politik, in: WI 13 (1931), S. 475 f.

BACHTfK, St., Německá emigrace v severovýchodních Čechách, in: NP 1 (1933), S. $32 \mathrm{f}$.

BAUER, Otto, Die Nationalitätenfrage und die Sozialdemokratie, Wien 1907.

BINDER, Karl, Der Zollpakt Deutschland-Österreich, in: Der Weg, Jg. 1931, S. 198-203.

DERS., Die Flucht aus dem Staatsverband der Tschechoslowakei, in: Der Weg 4 (1932), S. $25 \mathrm{f}$.

BLÁHA, M., Stát bez občanů, občané bez státu, in: „Základ“, Beilage zu: VOŽKP 1 (1919), S. 5 f.

BOHÁČ, V., Obchodní komory, in: Večerní České Slovo vom 27. 1.1919. 
BRAND, Walter, Die geistigen Grundlagen unserer Bewegung, Karlsbad 1935.

BRODA, Ernst, Benötigt die tschechoslowakische Republik zu ihrer wirtschaftlichen Lebensfähigkeit den Anschluß fremdnationaler Gebiete?, Wien 1921.

"CATO“, Velké Německo a sudetoněmecké hospodářství, čili máme se zařadit do německé čtyřletky?, in: HP 20 (1938), S. 433 f.

„CERTUS“, Budoucnost vývozu skleněné bižuterie, in: HP 20 (1938), S. 659-662.

DERS., Politický protektorát a jablonecký vývoz, in: HP 20 (1938), S. 786-789.

CHMELÁř́, Josef, Das deutsche Problem in der Tschechoslowakei, Prag 1936.

ČELAKOVSKÝ, Vladimír: Die Handels- und Gewerbekammern 1918-1928, in: Handels- und Gewerbekammern 1918-1928, S. 9-38.

VON DER DECKEN, Burghard, Die Wirtschaft der Tschechoslowakei, München/ Leipzig 1928.

DESET let Československé republiky, Band 2, Praha 1928.

DITTRICH, Erich, Die Tschechoslowakei in der Weltwirtschaft, in: WWA 40 (1934), S. 524-563.

DERS., Staatszerfall, Staatsneubildung und Wirtschaft, Leipzig 1937.

DODERER, Richard, Industrie und Politik, in: MDHI 2 (1921), S. 343-347.

„E.H.“, Deflationsbudget und Aufbauhypothese, in: WI 5 (1923), S. $379 \mathrm{f}$.

DERS., Der Kausalnexus im Wiederaufbau, in: WI 5 (1924), S. 419-421.

EISNER, Paul M., Schutz des inländischen Arbeitsmarktes, in: WI 10 (1928), S. $1023 \mathrm{f}$.

ENGLIŠ, Průmysl a politická soustava ve statě, in: ONH 42 (1937), S. 133-136.

DERS., Karel, Der „Deutsche Sozialismus“ als Programm der sudetendeutschen Partei. Eine kritische Analyse, Prag 1938.

ESCHENBURG, Theodor, Das Kaiserreich am Scheidewege, Berlin 1929.

EUROPÄISCHER NATIONALITÄTENKONGRESS (Hrsg.), Die Nationalitäten in den Staaten Europas, Wien 1931.

FERNEGG, Rudolf, Der angebliche Schutz des heimischen Arbeitsmarktes, in: BO vom 29.1. 1928.

DERS., Die ,Erfindung' des Deutschen Hauptverbandes der Industrie, in: WI 20 (1938), S. 3.

FISCHER, Adam, Unsere Braunkohlenindustrie, in: WI 5 (1924), S. 389.

DERS., Die Zukunft der böhmischen Braunkohlenindustrie, in: WI 6 (1924), S. $937 \mathrm{f}$.

FREYTAG, Hellmuth: Die Organisation der wirtschaftlichen und berufsständischen Selbstverwaltung in der Tschechoslowakei, Leipzig 1934.

GLÄNZEL, Gerhard, Die Wirtschaft der Tschechoslowakei in ihren Beziehungen zu Deutschland, Diss. Hamburg 1936.

GMELCH, Joseph, Die Gesetzesanträge Konrad Henleins vom April 1937, Diss. Würzburg 1940.

GOLDBERG, Heinrich, Die Konjunktursteuer, in: PT vom 4. 2. 1921.

GOLTZ, Otto F., Der Schutz des Arbeitsplatzes, in: WI 10 (1929), S. 345-347 und 363366.

GRUBER, Josef, Die Handels- und Gewerbekammer in Prag in den ersten fünfzig Jahren ihres Bestehens 1850-1900, Teil I und II, Prag 1900.

DERS., (Hrsg.), Czechoslovakia, New York 1924.

GRÜNFELD, EMIL A., Die endgültigen Aussichten der parlamentarischen Lösung des Kriegsanleiheproblems, in: MDHI 2 (1921), S. 349-351. 
GRUNTZEL, Josef, Mitteleuropäische Handelspolitik, in: MDHI 3 (1922), S. $871 \mathrm{f}$.

DERS., Freihandel oder Schutzzoll, in: MDHI 4 (1923), S. 89.

HACKER, Gustav, 1937: Kleiner aktivistischer Gewinn, in: WI 20 (1938), S. 1.

HAHN, Hans-Georg, Die Eingliederung der österreichischen und sudetendeutschen Wirtschaft in die Organisation des Altreiches, in: DV 1938, S. 1329-1330.

Die HANDELS- UND GEWERBEKAMMER IN PRAG, 1850-1900-1952, o.O., o.J.

Die HANDELS- UND GEWERBEKAMMERN 1918-1928. Jubiläumsschrift der Zentrale der tschechoslowakischen Handels- und Gewerbekammern anläßlich des zehnjährigen Bestandes der tschechoslowakischen Republik, Prag 1930.

HASSINGER, Hugo, Die Tschechoslowakei. Ein geographisches, politisches und wirtschaftliches Handbuch, Wien 1925.

HEGER, Erich, Ein sudetendeutscher Zusammenschluß, in: Der Ring 1 (1928), S. $616 \mathrm{f}$. HEINDL, Karl, Der Aufenthalt und die Beschäftigung von Ausländern auf dem Gebiete der tschechoslowakischen Republik, in: MDHI 6 (1925), S. $974 \mathrm{f}$.

HEJDA, Jiří, A opět: Politika a hospodářství. Obchodní komory, in: P̌̌ 4 (1927), S. $84 \mathrm{ff}$.

DERS., Die Handelskammern, in: WI 9 (1927), S. 55-57.

DERS., Komu patři československý průmysl, in: PŘ 4 (1927), S. 709-711, 724-726, 742$744,759-761,787-789,805-807,822-824$. - PŘ 5 (1928), S. 20-24, 38f., 54-56, 70-72, $86 \mathrm{f} ., 104 \mathrm{f} ., 117 \mathrm{f}$.

DERS., Hospodářské programy politických stran, in: PŘ 5 (1928), S. 713 f. und S. 804806.

DERS., Wirtschaftspolitik oder politische Wirtschaft?, in: WI 10 (1928), S. $1419 \mathrm{f}$.

DERS., Mraky na obzoru, in: HR vom 30.5.1929.

DERS., Co je se zákonem o obchodních komorách? in: Ȟ̌ vom 20.2. 1930.

DERS., Hospodářství a politika, in: Hř vom 13.3.1930.

HERDEGEN, Hans, Auslandsdeutschtum und Wirtschaft, in: Der Weg, Jg. 1930, S. 142-145.

HLAVÁČ, Bedřich, Katastrofa v Oseku, in: HA 13 (1934), S. $24 \mathrm{f}$.

HODÁČ, František, Industrielle Organisationsfragen, in: WI 2 (1921), S. $801 \mathrm{f}$.

DERS., Dr. Jaroslav Preiss in der Industrieorganisation, in: OB 12 (1930), S. 551-553.

HORNA, Miloš, Splynutí Rakouska s Německem s hospodářského zřetele, in: $\mathrm{ONH}$ 43 (1938), S. 199-203.

HOTOWETZ, Rudolf, Obchodní a živnostenské komory, in: HR vom 3.5. 1928.

JAHN, Rudolf (Hrsg.), Konrad Henlein spricht. Reden zur politischen Volksbewegung der Deutschen, Karlsbad-Leipzig 1937.

JANOVSKY, Karl, Die Wirtschaftskrise in der Tschechoslowakei, Reichenberg 1921.

DERS. (im Auftrag der deutschen Parlamentarier der Tschechoslowakei, herausgegeben im Auftrag des Deutschen Parlamentarischen Verbandes von der Deutschpolitischen Arbeitsstelle), Stellungnahme zu: Koloušek, Jan, La Situation économique et financičre de la République tchécoslovaque vers la Fin de l'Année 1920, Prag o.J. (1921).

DERS., Prag-Paris? Kritische Betrachtungen zum tschechisch-französischen Handelsvertrage, in: WI 2 (1921), S. 51-53.

DERS., Der Zwang zur Fakturierung in ausländischer Valuta, in: WI 2 (1921), S. $757 \mathrm{f}$. und 769-771.

DERS., Drei Jahre tschechoslowakischer Wirtschaftspolitik, Prag 1922. 
DERS., Die Produktionsgrundlage der Wirtschaft, in: MDHI 3 (1922), S. $359 \mathrm{f}$.

DERS., Die wirtschaftlichen Beziehungen der Tschechoslowakei zu Österreich, in: MDHI 4 (1923), S. 245-250.

DERS., Politik und Standesvertretung. Zur Spaltung der reichsdeutschen Spitzenorganisation der Industrie, in: WI 6 (1924), S. 111-113.

DERS., Zollunion Prag-Wien oder Anschluß Wien-Berlin, in: WI 9 (1927), S. 827-829 und 847-849.

DERS., Ausfuhrprämien, in: MDHI 16 (1935), S. 157 f. und S. 213-216.

DERS., Die Politik des ständischen Interessenausgleichs, in: ZT vom 25.12. 1935.

DERS., Donaupläne - augenblicklich sehr gefragt, in: ZT vom 10.1.1936.

DERS., Neuzeitliches Wirtschaftdenken, Karlsbad-Leipzig 1936 (2. Auflage, nach der Beschlagnahme).

DERS., Großdeutschland und die sudetendeutsche Wirtschaft, Karlsbad-Leipzig 1938.

JELLINEK, Fritz, Landwirtschaft und Industrie, in: PT vom 2. 3.1935.

JESSER, Franz, Mitteleuropäische Schicksalsfrage, Rede im Senat am 16.12.1930, in: Der Weg, Jg. 1931, S. 1-5.

K.R. („von einem Großindustriellen“), Die fehlende Einigkeit, in: OB 4 (1922), S. 7 ff.

KISLINGER, Josef, Industrielle Organisation, in: WI 3 (1922), S. $865 \mathrm{f}$.

DERS., Der Gedanke des Regionalismus, in: MDHI 16 (1935), S. $165 \mathrm{f}$.

KLUMPÁR, Vladislav, Industrielle Organisation, in: OB 1 (1921), S. 1 f.

KÖRBEL, Paul, Anspruch auf Arbeitsbescheinigung, in: PT vom 21.3.1936.

KOLOUŠEK, Jan, La Situation économique et financičre de la République tchécoslovaque vers la Fin de l'Année 1920.

KOTRBA, Milton, Ausländer und heimischer Arbeitsmarkt, in: MDHI 8 (1927), S. 908-910.

KREBS, HANS, Paneuropa oder Mitteleuropa?, München 1931.

DERS., Kampf in Böhmen, 1. Auflage Berlin 1936, 2. Auflage Berlin 1938.

KŘ́f̌̆, Karel, Henlein, vưdce do bídy, in: P̌̌ 15 (1938), S. 519-522.

KUFFNER, Hanuš, Unser Staat und der Weltfriede, Prag 1922.

KUKAŇ, V., Český lid, české menšiny a Národní Jednoty, in: NM 2 (1922), Nr. 2, S. 3 f.

DERS., Sokolstvo pro povznesení českých menšinách, in: NM 2 (1922), Nr. 3/4, S. 3.

KUNDT, Ernst, Zum zehnten Bestandsjahr des Deutschpolitischen Arbeitsamtes, in:

Der Weg, Jg. 1930, S. 20-22.

„L.S.“, Der österreichisch-deutsche Zollunionsplan und die Tschechoslowakei, in: WI 13 (1931), S. 647-649.

DER LEBENSWILLE des Sudetendeutschtums, Karlsbad-Leipzig 1938.

LECHER, Otto, Industrie und Parlament, in: MDHI 3 (1922), S. $819 \mathrm{f}$.

LEITSÄTZE zur Wirtschaftspolitik der Sudetendeutschen Partei. Zwei wirtschaftliche Reden von Konrad Henlein und Karl Janovsky, Karlsbad-Leipzig 1938.

MAREK, Josef, Průmysl v Československu a politika, in: HA 17 (1938), S. 225 f.

DERS., Naše obchodní jednání s Německem, in: HA 17 (1938), S. 305 f.

MAYER, Jindřich, Einige Bemerkungen zur Kritik der Handelskammern, in: WI 9 (1927), S. 559 f.

MEDINGER, Wilhelm, Die Industriekrise in der Tschechoslowakei, in: PT vom 27. 3. 1921.

DERS., Die politische Vertretung der Industrie, in: MDHI 2 (1921), S. 281-283. 
„M“ (MIXA), Rückkehr zu normalen Verhältnissen durch Lockerung der gebundenen Wirtschaft, in: OB 18 (1936), S. 1 .

MÜHLIG, Josef Max, Die politische Vertretung der Industrie. Eine Erwiderung, in: MDHI 2 (1921), S. 301-303.

DERS., Zu dem „Notplane“ der Masaryk-Akademie der Arbeit, in: MDHI 13 (1932), S. $562 f$.

DERS., Pohledy vpřed i zpět, in: HA 15 (1936), S. 7-10.

NAUMANN, Friedrich, Mitteleuropa, Berlin 1915.

NECKER, W., Hospodářsko-politické využití anšlusu, in: HP 12 (1938), S. 610 f.

PEROUTKA, Ferdinand, Naše německá otázka, in: PŘ 15 (1938), S. 1943.

PETERS, Gustav, Politik und Probleme der Zukunft, in: Der Weg, Jg. 1929, S. 365-371.

VON PHILIPPOVICH, Eugen, Ein Wirtschafts- und Zollverband zwischen Deutschland und Österreich-Ungarn, Leipzig 1915.

PIMPER, Antonín, Občanská koalice a naše hospodářská politika, in: HR vom 26. 10.1928.

DERS., Úkoly naší hospodářské politiky v zrcadle volebních výsledků, in: HA 14 (1935), S. 321.

DERS., Průmysl k hospodářské situaci, in: HA 14 (1935), S. $737 \mathrm{f}$.

POETSCHKE, Oswin, Das Staatsverteidigungs-Gesetz im Volkstumskampf der Tschecho-Slowakei, Dresden 1937.

DERS., Völker in Fesseln. Das Staatsverteidigungs-Gesetz im Volkstumskampf der Tschecho-Slowakei, (2. vermehrte Auflage) Dresden 1938.

POTUŽIL, František, Nejprve je nutno zabezpečiti stát, in: HA 14 (1935), S. 378.

PREISS, Jaroslav, O předpokladech zdárného hospodářského vývoje v budoucnosti, in: HA 17 (1938), S. 245 f.

PRIBRAM, Ewald, Die wirtschaftliche Lage des Sudetenlandes. Anschluß an das Deutsche Reich oder den tschecho-slowakischen Staat?, Wien 1919.

PROBLEME der tschechoslowakischen Republik. Kundgebungen des Präsidenten der Republik Dr. Edvard Beneš in Nordböhmen, Prag 1937.

RAUCHBERG, Heinrich, Der Schutz der heimischen Arbeit, in: WMÖHP 2 (1928), Nr. 2, S. 5 f.

SCHMOLKA, Walter, Gebühren von Aufenthaltsbewilligungen, in: PT vom 25. 8. 1935.

SCHOVÁNEK, A., Regionalismus v hospodářské správě, in: HA 14 (1935), S. 462 f.

SCHUSTER, Václav, K reformě obchodních a živnostenských komor, in: ONH 24 (1919), S. 52-60, 150-155 und 206-210.

SIMON, Walter, Sudetendeutsche Selbstverwaltung, Prag o.J.

STERN, Gustav, Wirtschaftliche Glossen, in: TA vom 29. 7. 1928.

SUDETENDEUTSCHE Beschwerde an den Völkerbund über den Erlaß des Ministeriums für nationale Verteidigung der Tschechoslowakischen Republik betreffend die Vergabe staatlicher Lieferungen, Karlsbad-Leipzig 1936.

TELTSCHER, Rudolf, Wirtschaftliche Diktatur. Ein Jahr tschechoslowakischer Wirtschaft,

in: WI 2 (1921), S. 472-474.

DERS., Wirtschaftskrise und Steuerdruck, in: PT vom 4. 5.1922.

DERS., Wirtschaft und Nationalismus, in: WI 3 (1929), S. $491 \mathrm{f}$. 
TERRITORIALE oder nationale Selbstverwaltung? Zweiter Teil: Kritik der Regierungsvorschläge, Karlsbad-Leipzig 1938.

TSCHERNE, Ernst (Hrsg.), Konrad Henlein, Heim ins Reich. Reden aus den Jahren 1937 und 1938, Karlsbad 1939.

UEBEL, Heinz-Adolf, Die Handelspolitik der Tschechoslowakei und ihre wesentlichen Entwicklungen von 1918 bis 1935, Nürnberg o.J.

UHLIG, Karl, Nur vorübergehender Unterkonsum, in: PT vom 13.3.1935, Beilage „Kohle und Eisen“, S. 13.

VANĚK, J., Einige Aufgaben der čechoslovakischen Wirtschaftspolitik vom Gesichtspunkte der Beschlüsse der Weltwirtschaftskonferenz aus, in: OB 9 (1927), S. 635-639 und S. 653-655.

VANÍK, Miloš, Nepronesená řeč Th. Liebiega, in: PŘ 15 (1938), S. 401-403.

VIŠKOVSKÝ, Alois, Der Zentralverband der tschechoslowakischen Industriellen im Jahre 1919, in: OB 2 (1920), S. 5-10.

Vom WESEN und Werden der Sudetendeutschen Heimatfront, Karlsbad 1934.

WALLNER, Julius, Zur Frage der industriellen Organisation, in: MDHI 2 (1921), S. 547-55o.

WEIL, Friedrich, Kritik der deutschböhmischen Industrie, in: WI 3 (1922), S. $511 \mathrm{f}$.

DERS., („F. W.“), Kopfloser Verzicht auf einen Kopf ?, in: WI 10 (1928), S. 883.

WINTERNITZ, Josef, Die Konzentration in der Industrie und im Bankwesen, in: PP vom 16.1.1927.

WIRTSCHAFTLICHE Fragen zum Anschluß Deutschböhmens und des Sudetenlandes an das Deutsche Reich, o.O., o.J.

WITT, Kurt, Wirtschaftskräfte und Wirtschaftspolitik in der Tschechoslowakei, Leipzig 1938.

WOLFRUM, Fritz, Industrie und Politik, in: MDHI 2 (1921), S. 347-349.

ZENKER, E.V., Freihandel oder Schutzzoll. Eine Erwiderung, in: MDHI 4 (1923), S. 42-44.

ZENTRALVERBAND der tschechoslowakischen Industriellen (Hrsg.), Průmysl o prostředcích k zmirnění nezaměstnanosti, Prag o.J. (1938).

ŽIVANSKÝ, Bohdan, Ústředna obchodních komor, in: NáL vom 20. 4. 1922. 


\section{Forschungsliteratur}

ALDERMAN, G. (Hrsg.), Governments, ethnic groups and political representation, Dartmouth 1992.

ALEXANDER, Manfred, Zusammenfassung und Schlußbetrachtung, in: SEIBT (Hrsg.), Chance, S. 255-261.

DERS., Zusammenfassung und Schlußbetrachtung, in: LEMBERG/HEUMOS (Hrsg.), Das Jahr 1919, S. 249-256.

ALTER, Peter, Nationalismus, Frankfurt/Main 1985.

BASCH, Antonin, Economic and Financial Policy of Czechoslovakia, 1918-1938, in: RECHCÍGL (Hrsg.), Czechoslovakia, S. 158-169.

BELLERS, Jürgen, Außenwirtschaftspolitik und politisches System der Weimarer Republik, Münster 1988.

BENEDIKT, Heinrich, Die wirtschaftliche Entwicklung in der Franz-Joseph-Zeit, Wien/München 1958.

BERDING, Helmut (Hrsg.), Wirtschaftliche und politische Integration in Europa im 19. und 20. Jahrhundert, Göttingen 1984.

BERGER, Peter-Robert, Der Donauraum im wirtschaftlichen Umbruch nach dem Ersten Weltkrieg, Wien 1982.

BEST, Heinrich, Politische Modernisierung und parlamentarische Führungsgruppen in Deutschland 1867-1918, in: HSR 13 (1988), S. 5-74.

BOHMANN, ALFRED, Bevölkerungsbewegungen in Böhmen 1847-1947 mit besonderer Berückichtigung der Entwicklung der nationalen Verhältnisse, München 1958.

DERS., Menschen und Grenzen, Band 4: Bevölkerung und Nationalitäten in der Tschechoslowakei, Köln 1975.

BOSL, Karl (Hrsg.), Aktuelle Forschungsprobleme um die Erste Tschechoslowakische Republik, München/Wien 1969.

DERS. (Hrsg.), Die Burg, Zwei Bände, München/Wien 1973.

DERS. (Hrsg.), Die demokratisch-parlamentarische Struktur der Ersten Tschechoslowakischen Republik, München/Wien 1975.

DERS. (Hrsg.), Gleichgewicht - Revision - Restauration, München/Wien 1976.

DERS. (Hrsg.), Die Erste Tschechoslowakische Republik als multinationaler Parteienstaat, München/Wien 1979.

BOYER, Christoph, Das Deutsche Reich und die Tschechoslowakei im Zeichen der Weltwirtschaftskrise, in: VfZ 39 (1991), S. 551-587.

DERS., Die Vergabe von Staatsaufträgen in der ČSR in den dreißiger Jahren - ein Vehikel zur Ruinierung der sudetendeutschen Wirtschaft? in: HOENSCH/KOVÁC̆ (Hrsg.), Scheitern, S. 81-117.

DERS./KUČERA, Jaroslav, Die Sudetendeutsche Heimatfront/Sudetendeutsche Partei und der Nationalsozialismus, in: MÖLLER/WIRSCHING/ZIEGLER (Hrsg.), Nationalsozialismus in der Region, S. 273-285.

BRANDES, Detlev, Die tschechoslowakischen National-Sozialisten, in: BOSL (Hrsg.), Multinationaler Parteienstaat, S. 101-153.

BROKLOVÁ, Eva, První československá ústava. Diskuse v ústavním výboru v lednu a únoru 1920, Praha 1992. 
BRÜGEL, Johann Wolfgang, Tschechen und Deutsche, Band 1 (1918-1938), München 1967.

BYSTRICKÝ, Valerián, Die diplomatischen und militärischen Voraussetzungen der Verteidigung der ČSR gegen die nationalsozialistische Aggression, in: HOENSCH/KOVÁČ (Hrsg.), Scheitern, S. 135-145.

CAMPBELL, Gregory, Confrontation in Central Europe. Weimar Germany and Czecho-slovakia, Chicago/London 1975.

CASSIS, Youssef, Wirtschaftselite und Bürgertum. England, Frankreich und Deutschland um 1900, in: KOCKA (Hrsg.), Bürgertum, S. 9-34.

CELOVSKY, Boris, Die Geschichte des Münchner Abkommens, Zwei Bände, Stuttgart 1958.

CESAR, Jaroslav/ČERNÝ, Bohumil, Politika německých buržoazních stran v Československu v letech 1918-1939, Zwei Bände, Praha 1962.

ČERNÝ, Bohumil, Wirtschaftliche Voraussetzungen der tschechoslowakischen Politik zwischen den Weltkriegen, in: Historica XI (1965), S. 177-215.

DENGG, Sören, Deutschlands Austritt aus dem Völkerbund und Schachts „Neuer Plan“, Frankfurt/Main 1986.

DEUTSCH, Karl W., Nation und Welt, in: WINKLER (Hrsg.), Nationalismus, S. 49-66.

DERS., Nationenbildung - Nationalstaat - Integration, Düsseldorf 1972.

DEYL, Zdeněk, Sociální vývoj Československa, 1918-1938, Praha 1985.

DOBRÝ, Anatol, Hospodářská krize československého prưmyslu ve vztahu k Mnichovu, Praha 1959.

DOERING, Dörte, Deutsche Außenwirtschaftspolitik, 1933-1935, Berlin 1969.

DOLEZEL, Stephan, Die deutsch-tschechoslowakischen Beziehungen von ihren Anfängen bis zum Ausgang der Ära Stresemann (1918-1929), in: BOSL (Hrsg.), Demokratisch-parlamentarische Struktur, S. 225-246.

EBERHARD, Winfried u.a. (Hrsg.), Westmitteleuropa - Ostmitteleuropa. Vergleiche und Beziehungen. Festschrift für Ferdinand Seibt zum 65. Geburtstag, München 1992.

EIBICHT, Rolf-Josef (Hrsg.), Die Tschechoslowakei - Eine Fehlkonstruktion. Die sudetendeutsche Frage bleibt offen, Berg 1993.

ELIAS, Norbert, Studien über die Deutschen. Machtkämpfe und Habitusentwicklung im 19. und 20. Jahrhundert, Frankfurt/Main 1990.

ELWERT, Georg, Fassaden, Gerüchte, Gewalt. Über Nationalismus, in: Merkur 45 (1991), S. 318-332.

ENGMAN, Max (Hrsg.), Ethnic identity in urban Europe, Dartmouth 1991.

FRANCIS, Emerich, Ethnos und Demos. Soziologische Beiträge zur Volkstheorie, Berlin 1965.

FRANKE, Reiner, London und Prag, Materialien zum Problem eines multinationalen Nationalstaates, 1919-1918, München 1981.

FROMMELT, Reinhard, Paneuropa oder Mitteleuropa, Stuttgart 1977.

GAJAN, Koloman, Irredentistická činnost nationalistických Němců a jejich podpora imperialistickými kruhy Německa v letech 1918-1923, in: Acta Universitatis Carolinae Pragensis - Philosophica et Historica 2 (1961), S. 43-75.

DERS., Německý imperialismus a československo-německé vztahy v letech 1918-1921, Praha 1962. 
GAWRECKÁ, Marie, K národnostní otázce v ČSR v letech 1918-1938, in: SLEZSKÝ ÚSTAV ČSAV (Hrsg.), Národnostní otázka, S. 16-19.

GEISSLER, Franz, Die Entstehung und der Entwicklungsgang der Handelskammern in Österreich, in: MAYER (Hrsg.), Hundert Jahre.

GELLNER, Ernest, Nationalismus und Moderne, Berlin 1991.

GESSNER, Dieter, Agrarprotektionismus und Welthandelskrise 1929/32, in: ZAA 26 (1978), S. 161-187.

GLASSL, Horst/PUSTEJOVSKY, Otfrid (Hrsg.), Ein Leben - Drei Epochen. Festschrift für Hans Schütz zum 70. Geburtstag, München 1971.

GLOTZ, Peter (Hrsg.), München 1938, Essen 1990.

GRUNER, Wolf D., Großbritannien und die Überlegungen zur politisch-wirtschaftlichen Neuorientierung im Donauraum, 1931-1937, in: SEIBT (Hrsg.), Böhmische Länder, S. 283-296.

HÁJEK, Jan, Ekonomická emancipace českého národa a jeho politický vývoj. Nástin nových úkolů naší historiografie, in: HD/EC 20 (1992), S. 267-272.

HARNA, Josef (u. a.), Materiály k politickým, hospodářským a sociálním dějinám Česko-slovenska v letech 1918-1929, Praha 1981.

DERS./LACINA, Vlastislav, Základní problemy vývoje agrárního hnutí v Československu v letech 1918-1939, in: SB 34 (1987), S. 87-131.

HECKMANN, Friedrich, Ethnische Minderheiten, Volk und Nation. Soziologie interethnischer Beziehungen, Stuttgart 1992.

HENTSCHEL, Volker, Zahlen und Anmerkungen zum deutschen Außenhandel zwischen dem Ersten Weltkrieg und der Weltwirtschaftskrise, in: ZfU 31 (1986), S. 95-116.

HEUMOS, Peter, Die Entwicklung organisierter agrarischer Interessen in den böhmischen Ländern und in der ČSR. Zur Entstehung und Machtstellung der Agrarpartei 1873-1938, in: BOSL (Hrsg.), Multinationaler Parteienstaat, S. 323-376.

DERS., Die große Camouflage? Überlegungen zu Interpretationsmustern der kommunistischen Machtübernahme in der Tschechoslowakei im Februar 1948, in: SCHMIDT-HARTMANN (Hrsg.), Kommunismus, S. 221-241.

HILF, Rudolf, Deutsche und Tschechen, Opladen 1973.

HOBSBAWM, Eric J., Nationen und Nationalismus. Mythos und Realität seit 1780 , Frankfurt/Main 1991.

HOCK, Wolfgang, Deutscher Antikapitalismus, Frankfurt/Main 1960.

HOENSCH, Jörg K., Geschichte der tschechoslowakischen Republik 1918-1978, Stuttgart 1978.

DERS., Geschichte Böhmens, München 1992.

DERS./KOVÁČ, Dušan (Hrsg.), Das Scheitern der Verständigung. Tschechen, Deutsche und Slowaken in der Ersten Republik, 1918-1938, Essen 1994.

HOLTFRERICH, Carl-Ludwig, Amerikanischer Kapitalexport und Wiederaufbau der deutschen Wirtschaft 1919 - 1923 im Vergleich zu 1924 - 1929, in: STÜRMER (Hrsg.), Weimarer Republik, S. 131-157.

HRABIK-SAMAL, Mary, Party organization as a crucial variable in the growth or loss of supporters. The case of the Republican Party in Inter-War Czechoslovakia, in: BOSL (Hrsg.), Multinationaler Parteienstaat, S. 377-402.

HROCH, Miroslav, Das Erwachen kleiner Nationen als Problem der komparativen Forschung, in: WINKLER (Hrsg.), Nationalismus, S. 155-173. 
JÄGGI, Christian J., Nationalismus und ethnische Minderheiten, Zürich 1993.

JANČ́́K, Drahomír, Německo a Malá dohoda, Praha 1991.

JAWORSKI, Rudolf, Vorposten oder Minderheit, Stuttgart 1977.

DERS., Grenzlage, Rückständigkeit und nationale Agitation. Die „Bayerische Ostmark" in der Weimarer Republik, in: ZBLG 41 (1978), S. 241-270.

DERS., Nationalimus und Ökonomie als Problem der Geschichte Ostmitteleuropas im 19. und zu Beginn des 20. Jahrhunderts, in: GG 8 (1982), S. 184-204.

DERS., Handel und Gewerbe im Nationalitätenkampf, Göttingen 1986.

DERS., The German Minorities in Poland and Czechoslovakia in the Interwar Period, in: SMITH (Hrsg.), Ethnic groups, S. 169-185.

JENAL, Manfred (Hrsg.), Gegenwart in Vergangenheit. Beiträge zur Kultur und Geschichte der Neueren und Neuesten Zeit. Festgabe für Friedrich Prinz zu seinem 65. Geburtstag, München 1993.

JINDRA, Zdeněk, Úvahy o česko-německých hospodářských vztazích na přelomu 19. a 20. století, in: HD/EH 20 (1992), S. 63-74.

KAPPELER, Andreas (Hrsg.), The formation of national elites, Dartmouth 1991.

KLUGE, Ulrich, Staat, Gesellschaft und Wirtschaft in Österreich 1848 bis 1945. Ausgewählte Beiträge historisch-politischer Forschung im Überblick, in: AfS XXII (1982), S. $606-649$.

KOCKA, Jürgen (Hrsg.), Bürgertum im 19. Jahrhundert. Deutschland im europäischen Vergleich, München 1988, S. 9-34.

KOŘALKA, Jiří, Vznik Československé republiky roku 1918 v oficiální politice německé říše, in: ČSČH 16 (1968), S. 819-848.

DERS., Die tschechische Bürgertumsforschung (= Universität Bielefeld, Sonderforschungsbereich 177, Arbeitspapier Nr. 5), o.O. 1989.

DERS., Tschechische Bergarbeiter in Nordwestböhmen und im Ruhrgebiet 1900-1914. Lebensbedingungen und Organisationen im Vergleich, in: EBERHARD (Hrsg.), West-mitteleuropa, S. 251-260.

KOSTA, Jiř́, Die sozialökonomische Entwicklung der ČSR, in: BOSL (Hrsg.), Demokratisch-parlamentarische Struktur, S. 7-33.

KOSTRBA-SKALICKY, Oswald, Bewaffnete Ohnmacht: Die tschechoslowakische Armee 1918-1938, in: BOSL (Hrsg.), Multinationaler Parteienstaat, S. 439-527.

KOTKIN, Joel, Tribes. How race, religion and identity determine success in the new global economy, New York 1993.

KRÁL, Václav, Otázky hospodářského a sociálního vývoje v českých zemích v letech 1938-1945, 3 Bände, Praha 1957-59.

DERS., Rezension von Alice Teichova „Příspěvek poznání zahraničních spojů finančního kapitálu v Československu“, in: ČSČH 6 (1958), S. 542-544.

DERS., K úloze zahraničního kapitálu v Československu před r. 1938, in: ČSČH 7 (1959), S. 473-478.

KRÜGER, Peter, Beneš und die europäische Wirtschaftskonzeption des deutschen Staatssekretärs Carl von Schubert, in: BO 14 (1973), S. 320-339.

DERS., Die Ansätze zu einer europäischen Wirtschaftsgemeinschaft in Deutschland nach dem Ersten Weltkrieg, in: BERDING (Hrsg.), Integration, S. 185-211.

KŘEN, Jan, Konfliktní společenství. Češi a Němci, 1780-1980, Praha 1990. 
KUBE, Alfred, Außenpolitik und „Großraumwirtschaft“. Die deutsche Politik zur wirtschaftlichen Integration Südosteuropas 1933 bis 1939, in: BERDING (Hrsg.), Integration, S. 185-211.

KUBU゚, Eduard, Německo - zahraničněpolitické dilema Edvarda Beneše. Hospodářské vztahy s Německem v československé zahraniční politice let 1918-1924, Praha 1994.

DERS., Die brüchigen Beziehungen: Die Weimarer Republik und die Tschechoslowakei, in: HOENSCH/KOVÁČ (Hrsg.), Scheitern, S. 15-28.

KURAL, VÁCLAV, Konflikt místo společenství? Češi a Němci v čskoslovenském státě, Praha 1993.

DERS., Die Tschechoslowakei als Nationalstaat? Das sudetendeutsche Problem, in: HOENSCH/KOVÁČ (Hrsg.), Scheitern, S. 63-70.

LACINA, Vlastislav, K místu Československu v evropské a světové ekonomice 19181938, in: ČSČH 26 (1978), S. 821-843.

DERS., Velká hospodářská krize v Československu, 1929-1934, Praha 1984.

DERS., Formování československé ekonomiky, Praha 1990.

DERS., Hospodářství českých zemí, 1880-1914, Praha 1990.

DERS., Alois Rašín, Praha 1992.

DERS., Nostrifikace podniků a bank v prvním desetiletí Českoslovenksé republiky, in: ČČH 92 (1994), S. 77-93.

LEMBERG, Hans, Die Tschechischen Konservativen 1918-1938, in: BOSL (Hrsg.), Aktuelle Forschungsprobleme, S. 113-131.

DERS., Das Erbe des Liberalismus in der ČSR und die nationaldemokratische Partei, in: BOSL (Hrsg.), Multinatinaler Parteienstaat, S. 59-78.

DERS./HEUMOS, Peter (Hrsg.), Das Jahr 1919 in der Tschechoslowakei und in Ostmitteleuropa, München 1993.

LEONCINI, Francesco, La questione dei Sudeti 1918-1938, Padova 1976.

DERS., Die Sudetenfrage in der europäischen Politik. Von den Anfängen bis 1938, Essen 1988.

LIPSCHER, Ladislav, Verfassung und politische Verwaltung in der Tschechoslowakei, 1918-1939, München/Wien 1979.

DERS., Beschwerden der Sudetendeutschen im wirtschaftlichen Bereich während der Ersten Tschechoslowakischen Republik, in: Jahrbuch für Zeitgeschichte 1982/83, S. 33-57.

LIPTÁK, L'ubomír, Der „Krach“ der tschechoslowakischen Staatsidee, in: HOENSCH/KOVÁČ (Hrsg.), Scheitern, S. 43-49.

MAMATEY, Victor S./LUŽA, Radomír (Hrsg.), Geschichte der Tschechoslowakischen Republik, 1918-1948, Wien 1980.

MATIS, Herbert, Österreichs Wirtschaft 1848-1913. Konjunkturelle Dynamik und gesellschaftlicher Wandel im Zeitalter Franz Josephs I., Berlin 1972.

MAYER, Hans (Hrsg.), Hundert Jahre österreichischer Wirtschaftsentwicklung 18481948, Wien 1949.

MILWARD, Alan S., Der deutsche Handel und der Welthandel, 1925-1939, in: MOMMSEN (Hrsg.), Industrielles System, S. 472-484.

MÖLLER, Horst/WIRSCHING, Andreas/ZIEGLER, Walter (Hrsg.): Nationalsozialismus in der Region. Beiträge zur regionalen und lokalen Forschung und zum internationalen Vergleich, München 1996. 
MOMMSEN, Hans (Hrsg.), Industrielles System und politische Entwicklung in der Weimarer Republik, Düsseldorf 1974.

NASSEHI, Armin, Zum Funktionswandel von Ethnizität im Prozeß gesellschaftlicher Modernisierung, in: Soziale Welt 41 (1990), S. 261-282.

NIESNER, Tomáš, Několik poznámek k výzkumu národněpolitických vztahů v průmyslových oblastech ostravska a horního slezska v meziválečném období, in: SLEZSKÝ ústav ČSAV, Národnostní otázka, S. 47-53.

NOVÁK, Otto, Die Henlainfaschisten (sic!) und München, in: Historica 27 (1987), S. 61-119.

NOVOTNÝ, Jiří, Pokusy zahraničního kapitálu o proniknutí do Živnostenské banky za predmnichovské ČSR, in: SSB 81 (1983), S. 31-44.

OLŠOVSKÝ, Rudolf, Světový obchod a Československo, 1918-1938, Praha 1961.

DERS. u.a., Přehled hospodářského vývoje Československa v letech 1918-1945, Praha 1961.

OTRUBA, Gustav, Das Kapital. Zusammenarbeit aus Sachzwang anstelle sachfremder Integration, in: SEIBT (Hrsg.), Chance, S. 63-86.

PLASCHKA, Richard G./MACK, Karlheinz (Hrsg.), Die Auflösung des Habsburgerreiches, München 1970.

POHL, Karl-Heinrich, Weimars Wirtschaft und die Außenpolitik der Republik, 19241926, Düsseldorf 1979.

POLZER, Robert, Die Tschechoslowakei im neuen Europa, in: GLASSL/PUSTEJOVSKY (Hrsg.), Ein Leben - Drei Epochen, S. 358-384.

PRINZ, Friedrich, Deutsche Geschichte im Osten Europas, Band 2: Böhmen und Mähren, Berlin 1993.

PRŮCHA, Václav (Hrsg.), Hospodářské dějiny Československa v 19. a 20. století, Praha 1974.

PRYOR, Frederic L./PRYOR, Zora P., Foreign Trade and Interwar Czechoslovak Economic Development, 1918-1938, in: VSWG 62 (1975), S. 500- 533.

PRYOR, Zora P., Außenhandel und Außenhandelspolitik, in: MAMATEY /LUŽA (Hrsg.), Geschichte, S. 211-216.

DIES., Die wirtschaftliche Entwicklung der Tschechoslowakei in der Zwischenkriegszeit, in: MAMATEY /LUŽA (Hrsg.), Geschichte, S. 211-216.

RADKAU, Joachim, Entscheidungsprozesse und Entscheidungsdefizite in der deutschen Außenwirtschaftspolitik 1933-1940, in: GG 2 (1976), S. 33-65.

RÁNKI, György, Economy and Foreign Policy. The Struggle of the Great Powers for Hegemony in the Danube Valley, 1919-1939, Boulder/Col. 1983.

RASCHHOFER, Hermann/KIMMINICH, Otto, Die Sudetenfrage, München 1988.

RAUPACH, Hans, Strukturelle und institutionelle Auswirkungen der Weltwirtschaftskrise in Ost-Mitteleuropa, in: VfZ 24 (1976), S. 38-57.

RECHCÍGL, Miloslav (Hrsg.), Czechoslovakia. Past and Present, The Hague/Paris 1968.

REICHERT, Günter, Das Scheitern der Kleinen Entente, München 1971.

ROTHSCHILD, J., East Central Europe between the Two World Wars, Seattle/London 1990.

SCHMIDT-HARTMANN, Eva (Hrsg.), Kommunismus und Osteuropa. Konzepte, Perspektiven und Interpretationen im Wandel, München 1994. 
SCHRAMM, Gottfried, Tschechen und Deutsche in der Ersten Republik, in: BO 29 (1988), S. 383-390.

SCHRÖTER, Harm, Siemens and Central and South-East Europe between the two World Wars, in: TEICHOVA/COTTRELL (Hrsg.), International business, S. 173192.

SCHRÖTER, Verena, The IG Farbenindustrie AG in Central and South-East Europe, 1926-1938, in: TEICHOVA/COTTRELL (Hrsg.), International business, S. 139172.

DIES., Die deutsche Industrie auf dem Weltmarkt, 1929-1933, Frankfurt/Main 1984.

SCHWARZ, Karl-Peter, Tschechen und Slowaken. Der lange Weg zur friedlichen Trennung, Wien/Zürich 1993.

SEEWANN, Gerhard (Hrsg.), Minderheitenfragen in Südosteuropa, München 1992.

SEGAL, Paul Harold, The French State and French Private Investment in Czechoslovakia, 1918-1938, New York/London 1987.

SEIBT, Ferdinand, Die Deutschen in der tschechischen Historiographie 1945-1985, in: GLASSL/PUSTEJOVSKY (Hrsg.), Ein Leben - Drei Epochen, S. 589-608.

DERS., Deutschland und die Tschechen, München 1974.

DERS. (Hrsg.), Die Böhmischen Länder zwischen Ost und West, München/Wien 1983.

DERS. (Hrsg.), Die Chance der Verständigung. Absichten und Ansätze zu übernationaler Zusammenarbeit in den böhmischen Ländern, 1848-1918, München 1987. DERS., Deutschland und die Tschechen (vollständig überarbeitete Neuausgabe), München 1993.

DERS., Eine sudetendeutsche Selbstdarstellung, in: BO 34 (1993), S. 151-155.

SKILLING, Gordon (Hrsg.), Czechoslovakia 1918-1988. Seventy Years from Independence, New York 1991.

SLÁMA, Jiří, Die Außenhandelsbeziehungen der ČSR mit Deutschland, in: BOSL (Hrsg.), Gleichgewicht, S. 217-233.

SLAPNICKA, Helmut, Majorities and Minorities in an Inverted position: Czechoslovakia, 1918-1939, in: VILFAN (Hrsg.), Ethnic groups, S. 173-195.

SLEZSKÝ ÚSTAV ČSAV (Hrsg.), Prưmyslový závod a oblast, Ostrava 1972.

DASS. (Hrsg.), Stav a perspektivy výzkumu průmyslových oblastí, Opava 1976.

DASS. (Hrsg.), Metodologické a metodické otázky výzkumu průmyslových oblastí za kapitalismu, Opava 1981.

DASS. (Hrsg.), Národnostní otázka v Československu (po roce 1918), Opava 1989 (interní tisk).

DASS. (Hrsg.), K hospodářským a sociálním dejinám 19. a 20. století, zwei Bände, Opava 1991.

SMELSER, Ronald, Die Henleinpartei. Eine Deutung, in: BOSL (Hrsg.), Multinationaler Parteienstaat, S. 189-201.

DERS., Das Sudetenproblem und das Dritte Reich, 1933-1938, München/Wien 1980.

SMITH, Paul (Hrsg.), Ethnic groups in international relations, Dartmouth 1990.

ŠOLLE, Zdeněk, Böhmen und Österreich, in: JENAL (Hrsg.), Gegenwart, S. 209-238.

STEGMANN, Dirk, Deutsche Zoll- und Handelspolitik 1924/5-1929 unter besonderer Berücksichtigung agrarischer und industrieller Interessen, in: MOMMSEN (Hrsg.), Industrielles System, S. 499-513.

DERS., „Mitteleuropa“ 1925-1934. Zum Problem der Kontinuität deutscher Außen- 
handelspolitik von Stresemann bis Hitler, in: DERS./WENDT/WITT (Hrsg.), Industrielle Gesellschaft, S. 203-221.

DERS./WENDT, Bernd-Jürgen/WITT, Peter-Christian (Hrsg.), Industrielle Gesellschaft und politisches System, Bonn 1978.

STEINER, Jan, K sociálně profesním strukturám Poláků a Němců v meziválečném Československu, in: SLEZSKÝ ÚSTAV ČSAV (Hrsg.), Národnostní otázka, S. 35-40.

STRUČNÝ hospodářský vývoj Československa do roku 1955, Praha 1969.

STÜRMER, Michael (Hrsg.), Die Weimarer Republik, Frankfurt/Main 1993.

SUGAR, Peter F./ LEDERER, Ivo J. (Hrsg.), Nationalism in Eastern Europe, Seattle/ London 1969.

TEICHERT, Eckart, Autarkie und Großraumwirtschaft in Deutschland, 1930-1939, München 1984.

TEICHOVA, Alice, Über das Eindringen des deutschen Finanzkapitals in das Wirtschaftsleben der Tschechoslowakei vor dem Münchner Diktat, in: ZfG 5 (1957), S. $1160-1180$.

DIES., K úloze zahraničního kapitálu v československém hospodářství před Mnichovem, in: ČSČH 7 (1959), S. 114-121.

DIES., An economic background to Munich, Cambridge 1974.

DIES., The Mannesmann concern in East Central Europe in the inter-war period, in: DIES./COTTRELL (Hrsg.), International business, S. 103-137.

DIES., Kleinstaaten im Spannungsfeld der Großmächte, München 1988.

DIES., Wirtschaftsgeschichte der Tschechoslowakei, 1918-1980, Wien 1988.

DIES./COTTRELL (Hrsg.), International Business and Central Europe, New York 1983.

DIES./M, Herbert (Hrsg.) Österreich und die Tschechoslowakei 1918-1938. Die wirtschaftliche Neuordnung in Zentraleuropa in der Zwischenkriegszeit, Wien/Köln/ Weimar 1996.

TROEBST, Stefan, Ethnien und Nationalismen in Osteuropa. Drei Vorüberlegungen zur vergleichenden historischen Forschung, in: ÖZG 5 (1994), S. 7-22.

ULLMANN, Hans-Peter, Interessenverbände in Deutschland, Frankfurt/Main 1988.

VENCOVSKÝ, František, Karel Engliš, Brno 1993.

VILFAN, Sergij (Hrsg.), Ethnic groups and language rights, Dartmouth 1990.

WAGNER, Richard, Panství kapitalistických monopolů v Československu, Praha 1958.

WALDMANN, Peter, Ethnoregionalismus und Nationalstaat, in: Leviathan 21 (1993), S. 391-406.

WALDRON, Arthur N., Theories of Nationalism and Historical Explanations, in: World Politics 37 (1985), S. 416-433.

WANDRUSZKA, Adam/URBANITSCH, Peter (Hrsg.), Die Habsburgermonarchie 1848-1918, Band 1 (Die wirtschaftliche Entwicklung), Wien 1973.

WEBER, Max, Wirtschaft und Gesellschaft. Grundriß der verstehenden Soziologie, Tübingen 1980 .

WEINBERG, Gerhard L., The Foreign Policy of Hitlers Germany, Chicago/London 1970.

WELISCH, Sophie A., Die sudetendeutsche Frage 1918-1928, München 1980.

WESSEL, Horst A., Kontinuität im Wandel. 100 Jahre Mannesmann, 1890-1990, Gütersloh o.J. 
WINGFIELD, Nancy M., Minority Politics in a Multinational State. The German Social Democrats in Czechoslovakia, 1918 - 1933, New York 1989.

WINKLER, Heinrich August, Weimar 1918-1933. Die Geschichte der ersten deutschen Demokratie, München 1993.

DERS. (Hrsg.), Nationalismus, Königstein/Ts. 1978.

WOTTAWA, Dietmar, Protektionismus im Außenhandel Deutschlands mit Vieh und Fleisch zwischen Reichsgründung und Beginn des Zweiten Weltkrieges, Frankfurt/ Main 1985.

WOYDT, Johann: Ausländische Arbeitskräfte in Deutschland. Vom Kaiserreich bis zur Bundesrepublik, Heilbronn 1987.

ZACEK, Joseph F., Nationalism in Czechoslovakia, in: SUGAR/LEDERER (Hrsg.), Nationalism, S. 166-206. 


\section{Perodika}

A-Zet

Allgemeine Thüringer Landeszeitung

Ascher Zeitung

Bayerische Staatszeitung

Berliner Börsen-Zeitung

Berliner Lokal-Anzeiger

Berliner Tageblatt

Bohemia

Die Börse

Börsen-Courier

Der Bund

Chebské hlasy

Čas

Čechoslovák

České slovo

Československá obrana

Československý deník

Český deník

Deutsche Allgemeine Zeitung

Deutsche Landpost

Deutsche Presse

Der deutsche Volkswirt

Deutsche Volkswirtschaft

Deutscher Angestelltenschutz

Dresdner Volkszeitung

Egerer Zeitung

Fränkischer Kurier

Genossenschaftliche Mitteilungen der Kreditanstalt der Deutschen

Gewerbe- und Handelszeitung

Hospodářská politika

Hospodářský archiv

Hospodářský parlament

Hospodářský rozhled

Hraničáŕ 
Journeé Industrielle

Kreuz-Zeitung

Leipziger Neueste Nachrichten

Lidové listy

Lidové noviny

Mährisches Tagblatt

Mitteilungen des Allgemeinen Deutschen Textilverbandes

Mitteilungen des Deutschen Hauptverbandes der Industrie

Mitteilungen des Sudetendeutschen Hauptverbandes der Industrie

Mitteilungen des Verbandes der Deutschböhmischen Textilindustriellen in Reichenberg und des mährisch-schlesischen Verbandes deutscher Textilindustrieller in Jägerndorf

Montagsblatt

Moravská orlice

Moravský večerník

Münchener Neueste Nachrichten

Národ

Národní demokracie

Národní listy

Národní obzor

Národní politika

Národní střed

Národnostní obzor

Národohospodářský přehled

Naše doba

Naše hranice

Naše menšiny

Neue Preußische Zeitung

Nordmährischer Grenzbote

Obrana národa

Observer

Obzor národohospodářský

Der Osteuropäische Volkswirt

Der Ost-Volkswirt

Osvěta lidu

Polední list

Pondělní Večerní list

Prager Arbeiterzeitung

Prager Presse

Prager Tagblatt

Právo lidu 
Preussische Jahrbücher

Př́tomnost

Reforma

Reichenberger Zeitung

Der Ring

Rote Fahne

Rudé právo

Rundschau

28. řijen

Saazer Anzeiger

Samostatnost

Severočeský dělník

Der Sozialdemokrat

Stráž Moravý

Tagesbote (Brünn)

Textilarbeiterzeitung

Textilrundschau

Tribuna

Večer

Večerní České slovo

Venkov

Verbandsnachrichten der deutschen Selbstverwaltungskörper in der Tschechoslowakischen Republik

Vẽstník ministerstva vnitra

Vẽstník obchodní a živnostenské komory v Plzni

Věstník ústředny československých obchodních a živnostenských komor

Völkischer Beobachter

Volk und Reich

Vossische Zeitung

Der Weg

Weltwirtschaftliches Archiv

Die Wirtschaft

Wirtschaft und Statistik

Wirtschaftliche Mitteilungen der österreichischen Handelskammer in Prag

Wirtschaftsdienst Hamburg

Der Wirtschafts-Ring

Die Zeit

Zeitschrift für Kommunalverwaltung

Zeitschrift für Politik

Zittauer Nachrichten und Anzeiger 


\section{Biographischer Anhang}

In den Anhang wurden im Regelfall nur Daten von Personen - meist des wirtschaftlichen Lebens - aufgenommen, die in anderen biographischen Sammelwerken nicht oder nicht in der wünschenswerten Ausführlichkeit verzeichnet sind. Für allgemein bekannte Persönlichkeiten aus den ersten Reihen der Politik wie Masaryk, Beneš oder Beran wird auf die gängigen Informationsmittel wie das Československý biografický slovník verwiesen. Ausnahmen sind Spitzenpolitiker von zentraler Bedeutung auch für die Wirtschaft wie Engliš oder Rašín. Die Kurzbiographien erstrecken sich nur auf den in dieser Studie behandelten Zeitraum, d. h. bis zum Ende der Ersten Republik.

BACHER, Franz (1884-1945), Dr. jur., prominenter Wirtschaftsjournalist, zusammen mit Friedrich Weil Herausgeber der "Wirtschaft“" Von 1919 bis 1938 außerdem Chefredakteur der deutschen Zeitung „Bohemia“. Seit 1919 Mitglied der Deutschdemokratischen Freiheitspartei (DDFP), zur Zeit der Fusionierung der DDFP mit der Rosche-Peters-Gruppe zur DAWG deren Reichsleitungsmitglied, von 1931 bis 1935 Abgeordneter des Parlaments. Seit 1934/35 Hauptfigur der wiedergegründeten DDFP: Vgl. Balling, Von Reval bis Bukarest, Band 1, S. 288.

BÁRTA, Rudolf (1868-?), aus alter industrieller Familie stammend (der Vater hatte die Produktion von Portlandzement in Böhmen eingeführt); Generaldirektor des Großbauunternehmens Bárta und Tichý (später Prastav A.G.). Vor 1914 zahlreiche Funktionen im Verbandswesen der keramischen und der Baustoffindustrie. Nach 1918 Vorsitzender des Vereins der Kalkindustrie und der keramischen Sektion des Zentralverbands: Vgl. OB 20 (1938), S. $219 \mathrm{f}$.

BAUMGARTNER, Karl (1874-1931), Dr. ing., seit 1917 Zentraldirektor der Brucher Kohlenwerke AG Teplitz, später dort im Verwaltungsrat: Vgl. MDHI 16 (1935), S. 31 .

BAXA, Karel (1863-1938), Jurist, seit 1911 Mitglied der volkssozialistischen Partei, 1895-1913 Abgeordneter der böhmischen Landesversammlung, 1901-1918 des Wiener Reichsrats. 1919-1937 Oberbürgermeister von Prag, ab 1920 Vorsitzender des Verfassungsgerichts, ab 1923 Vorsitzender des Verwaltungsrats der Česká banka: Vgl. ČBS, S. 31.

BAYER, Anton (Antonín) (Lebensdaten nicht zu eruieren), 1902 in die Kammer Pilsen gewählt. Seit 1907 im Verwaltungsrat der Pilsener Aktienbrauerei; deren Präsident ab 1918: Vgl. SÚA, MPOŽ, Karton 550, sek 1/8 261/24/27-28, Klub der deutschen Minderheit der Handels- und Gewerbekammer Pilsen an MPOŽ, 19. 10. 1927.

BONDY, Léon (?-1923), 1902 Mitglied der Prager Handels- und Gewerbekammer. 1903 deren einstweiliger Vorsitzender, 1909 Vizevorsitzender. In diesem Amt bestätigt 1919. Tätig in zahlreichen Ausschüssen und Instituten der Kammer, z. B. Leiter des Exekutivausschusses für die Jubiläumsausstellung der Kammer 1908. Nach 1918 zeitweilig Vorsitzender des Beirats für volkswirtschaftliche Fragen und Vorsitzender der Aus- und Einfuhrkommission. Ab 1922 auch in der Kammerzentrale, als deren amtierender Vizepräsident, dort von maßgeblichem Einfluß: Vgl. SÚA, MPOŽ, Karton 520, Protokoll der außerordentlichen Versammlung der Verwal- 
tungskommission der Handels- und Gewerbekammer Prag am 15. 10. 1923 anläßlich von Bondys Tod. - WI 5 (1923), S. 409.

BONDY, Léon (1875-1934), Inhaber des Bankhauses Fischl und Bondy. Nach dem Besuch der Handelsakademie und Tätigkeit in der Bank Rosenfeld und Co., Wien 1896 Eintritt in die Kabelfabrik Wien, 1901 in die „Kabel Bratislava“. 1910 dort Direktor. 1917 in den Verwaltungsrat gewählt, ab 1924 Generaldirektor, 1930 Verwaltungsratspräsident. Das Unternehmen erlebte unter Bondy einen großen Aufschwung und expandierte nach Krakau und Budapest. Verwaltungsratsmitglied der Böhmischen Union-Bank und einer ganzen Reihe von Industrieunternehmen. Präsident des Beirats für wirtschaftliche Fragen ab 1920; seit 1922 Präsident der Zentralvereinigung der slowakischen Industrie, Vizepräsident der Verwaltungskommission der Handels- und Gewerbekammer Bratislava und Vizepräsident des Zentralverbands: Vgl. OB 16 (1934), S. 80 f. - ONH 25 (1920), S. 229.

BOUČEK, Václav (1869-1940), Anwalt. Vor 1918 Aktivist in Masaryks Realistenpartei, 1918-1920 als Mitglied der Tschechoslowakischen Fortschrittspartei Angehöriger der Revolutionären Nationalversammlung, dort maßgeblich an der Ausarbeitung der Verfassung beteiligt. Zwischen 1925 und 1930 Mitglied der „Nationalen Arbeitspartei“, einer Abspaltung der Nationaldemokraten, die schließlich in den Volkssozialisten aufging: Vgl. ČS, S. 62. - NSČPRR, S. 302.

BRASS, Hermann (?-1938), Seniorchef der bedeutenden Textilfirma Wilhelm Brass und Söhne in Hohenstadt: Vgl. TR 20 (1938), S. 283.

CICHORIUS, Theodor (1864-1933), gebürtiger Reichsdeutscher, Besitzer von Textilbetrieben in Sachsen, Österreich und Böhmen. 1893 Mitbegründer der Industriellengewerblichen Vereinigung, 1900 Mitbegründer und Vorsitzender des Verbandes nordböhmischer Industrieller in Reichenberg, der im September 1920 in den Deutschen Arbeitgeberverband umgewandelt wurde. Außerdem Mitglied im Präsidium des Zentralverbandes der Industriellen Österreichs, Mitbegründer und Vizepräsident des DHI und des Allgemeinen Deutschen Textilverbandes. Mitte 1928 wegen der Übersiedlung nach Dresden Niederlegung aller Ämter: Vgl. MDHI 9 (1928), S. 659. - Bericht über die Verbandsgeschichte auf der Jubiläums-Vollversammlung des DHI am 21. 9. 1929, in: MDHI 10 (1929), S. 767. - MDHI 14 (1933), S. 481.

DODERER, Richard (Lebensdaten nicht zu eruieren), Ingenieur und Werksdirektor in Komotau, Leiter der Bezirksgruppe Komotau des DHI: Vgl. MDHI 3 (1922), S. 205.

DRACHOVSKÝ, Josef (1876-1961), Beamter der staatlichen Finanzverwaltung, zuletzt Vorstand des Präsidiums der Finanzlandesdirektion in Prag; seit 1909 Professor an der Prager Karls-Universität, 1917/18 und 1932/33 Dekan, 1934/35 Rektor: Vgl. ČBS, S. 117. - BLGBL, Band 1, S. 276.

DYK, Viktor (1877-1931), seit 1900 freier Schriftsteller. Tätigkeit im heimischen Widerstand, 1916-17 Haft in Wien. Journalistische Tätigkeit, u. a. 1910-1914 Redakteur der „Samostatnost“. Seit 1918 Redakteur der „Národní listy“ und führender Politiker der Nationaldemokraten. 1918-1925 Abgeordneter, ab 1925 Senator: Vgl. ČBS, S. $128 \mathrm{f}$.

ENGLIŠ, Karel (1880-1961), Ökonom, Philosoph, Jurist, Pädagoge. Ab 1917 Professor für Volkswirtschaftslehre am Tschechischen Technikum in Brünn, 1919 Professor und erster Rektor der Masaryk-Universität in Brünn, 1913-1918 Abgeordneter der mährischen Landesversammlung, 1920-1925 nationaldemokratischer Abgeordner der Nationalversammlung. 1920-1931 mehrere Male in verschiedenen Regierungen Fi- 
nanzminister, 1934-1939 Gouverneur der Nationalbank: Vgl. ČBS, S. 132f. - Vencovský, Engliš.

FAFL, Zdeněk (1861-1961), Jurastudium in Wien und Prag, 1924 Dr. jur. Seit 1927 Beamter der Prager Kammer, ab 1932 deren Generalsekretär. 1927 bis 1939 auch Generâlsekretär des Tschechoslowakischen Exportinstituts: Vgl. BLGBL, Band 1, S. $324 \mathrm{f}$.

FREISSLER, Robert (1877-1950), Handelskammersekretär und Landeshauptmann der - von Oktober bis Dezember 1918 existierenden - mährisch-schlesischen Provinz „Sudetenland“: Vgl. Balling, Von Reval bis Bukarest, Band 1, S. 40.

GINZKEY, Willy (Lebensdaten nicht zu eruieren), Chef der Textilfirma J. Ginzkey in Maffersdorf, 1921 in den Vorstand des Allgemeinen Deutschen Textilverbandes gewählt: Vgl. den Bericht über die ordentliche Vollversammlung des ADTV am 3. 4. 1921, in: MADTV 3 (1921), S. 87-93, hier S. 89.

GOLTZ, Otto (1865-?) , Textilindustrieller, Gründungsmitglied des DHI, Motor bei der Eingliederung des Arbeitgeberverbandes in den DHI. Nach Cichorius' Abgang bis 1934 Leiter der Arbeitgeberhauptstelle. Außerdem Gründungs- und Vorstandsmitglied des ADTV: Vgl. MDHI 16 (1935), S. $436 \mathrm{f}$.

GRUBER, Josef (1865-1925), tschechischer Nationalökonom, seit 1909 Professor für Volkswirtschaftslehre an der Tschechischen Universität Prag: Vgl. BLGBL, S. 477. - ČBS, S. $174 \mathrm{f}$.

HAJN, Antonín (1868-1949), Publizist und Verleger, Herausgeber der „Samostatnost“. 1907-1911 im Reichsrat Sprecher der nationaltschechischen Opposition und Vorkämpfer eines selbständigen tschechischen Staates. Im einheimischen Widerstand. Mitglied des Nationalausschusses. 1918-1935 nationaldemokratischer Abgeordneter: Vgl. ČBS, S. 183.

HODÁČ, František (1883-?), Studium der Rechte; Promotion zum Dr. jur. 1907. Wie seine ganze Studentengeneration geprägt vom Kampf der Prager Studenten und Arbeiter um das allgemeine Wahlrecht, der im Jahre 1907 seinen Höhepunkt erreichte. In diesem Zusammenhang Profilierung als Führer der jungen Generation. „Sokolistisch" und national ausgerichtet. Vielfältige kulturelle Interessen, u.a. Theaterkritiker der „Lidové Noviny“. Studium der Nationalökonomie. Habilitation am Technikum in Brünn als Dozent für Volkswirtschaftslehre, Finanzwissenschaft und Statistik. Ab 1922 ordentlicher Professor der Volkswirtschaft an der Universität Prag. Bereits mit 25 Jahren Mitglied des Präsidiums und stellvertretender Vorsitzender der fortschrittlichen Volkspartei, außerdem Obmann des Brünner Sokolgaus. 1911 Sekretär des mährischen Industriellenvereins. Generalsekretär des Zentralverbandes der tschechoslowakischen Industriellen, in dieser Funktion Vertreter des Zentralverbands u. a. im Bankausschuß beim Finanzministerium. Nach der Errichtung der Nationalbank Mitglied des Bankrates und des Bankausschusses. Niederlegung beider Ämter mit der Wahl zum Abgeordneten der Nationaldemokratischen Partei 1929. Mitglied des Budgetausschusses des Abgeordnetenhauses, des Budgetsiebenerausschusses, der Spar- und Kontrollkommission und des ständigen Parlamentsausschusses in der Nationalversammlung. Motor hinter der Gründung der Konföderation der tschechoslowakischen Arbeitgeberorganisationen, ab 1927 dort Vorsitzender und in dieser Funktion Mitglied des Verwaltungsausschusses des Internationalen Arbeitsamtes. 1923 Mitglied der gemischten Kommission für Abrüstungsfragen, 1929 des Vorbereitungsausschusses für die Internationale Welthandelskonferenz in Genf. 
1933 Rückzug auf den Posten eines Vizepräsidenten des Zentralverbands: Vgl. OB 15 (1933), S. 247-250 und S. 283. - WI 15 (1933), S. 283.

HOTOWETZ, Rudolf (1865-?), Jurist, nach kurzer Tätigkeit bei der Statthalterei Prag ab 1891 Konzeptbeamter und ab 1903 leitender Sekretär der Prager Handels- und Gewerbekammer. Ab 1900 auch im Zentralverband der österreichischen Industriellen tätig, dort durch vielfältige Anregungen zum Zolltarif Profilierung als Außenhandelsexperte. Im Kriege Vorkämpfer für die Interessen der tschechischen Wirtschaft. 1918 Leiter der Aus- und Einfuhrkommission. 1920-21 Minister für Außenhandel im Beamtenkabinett Černý. Dort Vorbereitung der Zolltarifreform. Seit 1921 Präsident des Allgemeinen Pensionsinstituts. Auch in der Folgezeit Wahrnehmung einer Fülle von (Ehren-)ämtern im Wirtschaftsleben der Republik: Vgl. OB 17 (1935), S. 236.

JEŠEK, František (1890-1969), Journalist, tätig u.a. für die „Národní listy“ und den „Národ“. 1923-1933 Geschäftsführer des zentralen Exekutivausschusses der nationaldemokratischen Partei, 1933-1938 stellvertretender Vorsitzender der Partei bzw. der Nationalen Vereinigung. 1925-1939 Abgeordneter, 1938 Gesundheitsminister: Vgl. ČBS, S. 279.

JIRÁSEK, Alois (1851-1930), Dramatiker und Verfasser historischer Romane. Im Mai 1917 Unterzeichner des „Manifests tschechischer Schriftsteller“. Mitglied der revolutionären Nationalversammlung, 1920-1925 nationaldemokratischer Senator: Vgl. ČBS, S. 283.

KARLÍK, Hanuš (1850-?), Angehöriger der Generation, die den Grundstein für die wirtschaftliche Emanzipation der Tschechen legte. Chemiker und Ingenieur, seit 1870 befaßt mit den technischen Problemen der Zuckerproduktion. Seit 1874 auf verschiedenen leitenden Posten in der Zuckerindustrie tätig. In einer Reihe wichtiger Positionen in der wirtschaftlichen Selbstverwaltung, insbesondere in den Verbänden der überwiegend tschechischen Industriebranchen. U.a. Gründer des Vereins der Zuckerindustrie in Böhmen, Vertreter der tschechischen Zuckerinteressen in Wien, Präsident des Zentralvereins der tschechischen Zuckerindustrie: Vgl. OB 9 (1927), S. $37 \mathrm{f}$.

KIRCHHOF, Carl (Karel) (1852-1929). Nach dem Studium an der Hamburger Handelsakademie in Reichenberg Gründung eine Kommissionsfirma für Wolle, Leder, Farben und Chemikalien. Außerdem Inhaber einer Baumwollhandelsfirma. Mitglied der Reichenberger Kammer ab 1880; 1891 zum provisorischen Vorsitzenden, 1915 zum Kammerpräsidenten gewählt. Seine Verdienste erkannte nach dem Umsturz auch die neue Regierung an; von dieser zum Präsidenten der Verwaltungskommission ernannt: Vgl. MDHI 3 (1922), S. 35. - WI 11 (1929), S. 1182.

KOVÁŘ́K, František (1865-?), vor 1918 Vorsitzender der Brünner Industriellenvereinigung, verkörpert die mährischen Wurzeln des Zentralverbands. Nach Realschule und technischer Ausbildung in Wien 1894 Gründung eines Unternehmens zur Produktion landwirtschaftlicher Maschinen, das, 1909 in eine Aktiengesellschaft umgewandelt, mit mehr als 900 Beschäftigten und modernster technischer Ausrüstung in der Branche bald eine Spitzenstellung errang. „Multifunktionär“ in der Politik wie in der Selbstverwaltung der Wirtschaft: 1910 Vizepräsident im Verband der Fabriken landwirtschaftlicher Maschinen, nach der Gründung der Republik Vorsitzender des Beirats für wirtschaftliche Fragen, außerdem Mitglied der Verwaltungskommission der Handels- und Gewerbekammer Olmütz. 1921 im ersten Kabinett Černý (Beamtenkabinett) Minister für öffentliche Arbeiten. 1929 Mitglied der mährischen Landes- 
vertretung. In der Politik insbesondere als Vorkämpfer für eine Reform der öffentlichen Verwaltung hervorgetreten: Vgl. OB 15 (1933), S. 248 und 17 (1935), S. 217 f.

KREJČÍ, František Václav (1867-1941), Journalist, Essayist und Theaterkritiker. Mitglied der revolutionären Nationalversammlung, 1920-1935 Senator: Vgl. ČBS, S. 364.

LIEBIEG, Theodor (1872-1939), wie Heinrich Schicht in der dritten Generation Angehöriger einer prominenten Industriellendynastie. Sein Großvater Johann hatte 1828 das Reichenberger Textilhandels-, später auch Produktionsunternehmen mit einer Filiale in Wien gegründet, das der Vater, Theodor Liebieg d. Ä., fortführte. Durch diesen auch Erwerb des Baronats. Die Familie besaß - charakteristisch für die Tendenz zur Feudalisierung altetablierter Industriellenfamilien - außer ihren Unternehmen ausgedehnte Ländereien in den Karpaten. 1889 Eintritt in das Geschäft, 1891 nach dem Tode des Vaters Übernahme der Leitung. Der jüngere Bruder Gisbert war Chef der Wiener Niederlassung. 1930 Aufnahme von Liebiegs Schwiegersohn, des reichsdeutschen Diplomaten Roland Köster, als dritter Teilhaber in den Wiener Betrieb. Vor dem Ersten Weltkrieg einer der bedeutendsten europäischen Industriellen. Nach dem Krieg durch die Textilkrise in den Hintergrund gedrängt; stufenweise Reduzierung der Produktion auf den Wollsektor. Schwer in Mitleidenschaft gezogen durch die Weltwirtschaftskrise; Zwang zur Reorganisierung bzw. zu teilweisen oder vorübergehenden Stillegungen. Wegen der starken Inanspruchnahme durch diese Arbeiten Anfang 1932 Aufgabe der Präsidentschaft der Böhmischen Union-Bank, in deren Verwaltungsrat Liebieg 30 Jahre lang gesessen hatte. Rückzug von den Aufsichtsratsmandaten - u.a. bei der Ersten Böhmischen Kunstseidenfabrik Theresienthal, der Duxer Kohlengesellschaft in Teplitz, der Siemens A.G. in Prag und bei zahlreichen deutschen Textilunternehmen. Bis 1918 Abgeordneter im österreichischen Herrenhaus, dort eingezogen als jüngstes Mitglied. Stadtrat in Reichenberg. Nach 1914 als Präsident des Kriegsverbandes der Wollindustrie und der Wollzentrale A.G. Betätigung in der Kriegswirtschaftsverwaltung. Nach 1918 Mitglied im Präsidialausschuß des Zentralverbands und des DHI, Vorsitzender des Allgemeinen Deutschen Textilverbandes. Zusätzlich zu seinen Ämtern im wirtschaftlichen Verbandswesen im September 1929 zum Vorsitzenden der Verwaltungskommission der Handels- und Gewerbekammer Reichenberg ernannt; dort bereits seit 1903 Mitglied und 1915-1917 Vizepräsident. Zudem Präsident der Reichenberger Messe. Im Zuge der Nazifizierung des DHI im Juni 1938 als Nachfolger Mühligs Präsident des Verbandes. Anläßlich der Annexion des Sudetenlandes hervorgetreten durch eine peinlich-servile „Huldigung“ an die Adresse des „Führers“. Unter dem neuen Regime treuhänderischer Leiter des ADTV und des Sudetendeutschen Hauptverbandes der Industrie, der Nachfolgeorganisation des DHI, als solcher für die Eingliederung der beiden Verbände in die Wirtschaftsorganisation des Reiches zuständig. Bereits nach einigen Monaten, angeblich aus gesundheitlichen Rücksichten, Rücktritt von allen Ämtern: Vgl. TR 21 (1939), S. 31, 131, 139f. - WI 10 (1928), S. 999 f., 11 (1929), S. 1286, 12 (1930), S. 543, 915, 21 (1939), S. 27. - MDHI 18 (1937), S. 272. - HR vom 3.3.1932. - BÖ vom 13.3. 1932.

MALINSKÝ, František (1850-1926), zunächst Distriktsarzt, Bürgermeister und Bezirksvorsteher in Hlinsko, dann Gründung eines nahrungsmittelverarbeitenden Unternehmens. 1891 Aufgabe der ärztlichen Praxis. In Ronov an der Sázava Übernahme einer Fabrik. Vor 1914 an prominenter Stelle in der Selbstverwaltung der Wirtschaft 
tätig: 1903 Vorsitzender des österreichischen Glukosekartells, 1907 stellvertretender Vorsitzender der von ihm gegründeten Genossenschaft der landwirtschaftlichen Spiritusbrennereien, 1909 Präsident der Prager Handelskammer. Engagiert in der tschechischen Emanzipationsbewegung; für die Jungtschechen im Landtag. 1911 Eintritt in den Verwaltungsrat der Živnostenská Banka, zunächst als stellvertretender, dann als erster Vorsitzender; im Krieg Leiter der Bank wie der Prager Kammer. Im Zentralverband einer der „Männer der ersten Stunde“. Aus gesundheitlichen Gründen 1920 Rückzug aus der Bank und aus dem Zentralverband, aber weiter an der Spitze der Prager Kammer. Politisch nach dem Kriege als Abgeordneter der Verfassunggebenden Nationalversammlung und als Senator in der ersten gewählten Nationalversammlung tätig: Vgl. die Würdigungen zum 75. Geburtstag in: OB 7 (1925), S. 563 und anläßlich seines Todes in: OB 7 (1926), S. 181.

MAŘíK, Bohuslav (1854-1929), Absolvent der tschechischen Hochschule in Prag, ab 1878 als Ingenieur in der böhmisch-mährischen Maschinenfabrik (später ČKD) tätig, die vor allem die Fertigung von Maschinen für die Zuckerproduktion betrieb. Dort Aufstieg vom Techniker zum Direktor; als solcher unter anderem verantwortlich für die Gründung einer Automobil-Abteilung. Im Krieg Mitglied des Verwaltungsrats der ČKD. 1920 nach dem Rücktritt Malinskýs Präsident des Zentralverbands: Vgl. OB 6 (1924), S. 13 f. und die Gedenkrede von Jaroslav Preiss anläßlich des Begräbnisses am 29.11.1929 in: OB 11 (1929), S. 499 f.

MEDINGER, Wilhelm (1878-1934), Gutsbesitzer aus dem Bezirk Gablonz. 1908-1913 als Vertreter der verfassungstreuen Gutsbesitzer Abgeordneter im Böhmischen Landtag, ab 1919 Vizepräsident des Verbandes der deutschen Großgrundbesitzer Böhmens und Vorsitzender der Deutschen Völkerbundliga in der ČSR ab deren Gründung 1922. Als internationaler Kongreßteilnehmer genötigt, sich von seiner Partei, der DNP, zu distanzieren. Im November 1922 Austritt aus der DNP-Fraktion. Zunächst fraktionslos, schließlich im Klub der fraktionslosen deutschen Abgeordneten. 1925 von der DNP nicht wieder aufgestellt; wegen seines internationalen Renommees wurde ihm jedoch von den Deutschen Christlich-Sozialen ein sicheres Senatsmandat eingeräumt. 1925-32 Senator für den Bezirk Königgrätz: Vgl. Balling, Von Reval bis Bukarest, Band 1, S. 329.

MÜHLIG, Josef Max (1874-?), 1892 Eintritt als Betriebsingenieur in die Glasfabrik des Vaters, zusammen mit seinem Bruder bald deren technischer Leiter. Renommierter Experte, Pionier der mechanischen Erzeugung von Flaschen- und Tafelglas. Gründungsmitglied des DHI; Leiter des Verbands zuerst zusammen mit dessen erstem Vorsitzenden Schicht, dann anstelle Schichts, als dieser aufgrund seines wachsenden Auslandsengagements mehr und mehr in den Hintergrund trat. 1932 bis zur Ablösung Anfang Juni 1938 auch formell Vorsitzender. Mitglied der Bezirksvertretung, des Stadtrats Teplitz, Mitglied der Verwaltungskommission der Handels- und Gewerbekammer Reichenberg, Präsident des Vereines der Freunde der Technischen Hochschule Prag, Gründer und bis 1927 Vorsitzender des Arbeitgeberverbandes der Glasindustriellen in Teplitz, Mitglied im Wirtschaftsverband der Glasindustriellen der Tschechoslowakischen Republik in Prag, des Präsidialausschusses des Zentralverbands sowie dessen Vizepräsident von Amts wegen nach dem Zusammengehen der beiden industriellen Organisationen. Einer der prominentesten Vertreter nicht nur des deutschen, sondern des gesamtstaatlichen wirtschaftlichen und politischen Le- 
bens der Ersten Republik: Vgl. die Würdigungen zum 60. Geburtstag in: MDHI 15 (1934), S. 1 und in OB 16 (1934), S. 10f. - HR vom 3.10.1929. - Bericht über die auBerordentliche Vollversammlung des DHI am 2.6.1938, in: MDHI 19 (1938), S. 233. NAJMAN, Josef V. (1882-1937), gelernter Kolonialwarenhändler. Frühzeitig Engagement für den gewerblichen Mittelstand, 1905 Gründer der Zeitschrift „Naše obrana“ (Unsere Verteidigung), 1906 der „Obchodnické zájmy“ (Handelsinteressen). In der Folgezeit Kontrolle über eine Reihe weiterer, die parteipolitische Vertretung der Mittelstandsinteressen propagierender Blätter. Zusammen mit Rudolf Mlčoch Gründer der Tschechischen Gewerbepartei. 1919 Reorganisation der Partei durch Mlčoch und Najman als - so der neue Name - Mittelstandspartei des Handels und Gewerbes. 1920 war diese mit sechs Abgeordneten, darunter Najman, in der Kammer vertreten. 1925 zunächst Vorsitzender der Parlamentsfraktion und, nach der Bildung des Bürgerblocks, von Oktober 1926 bis Dezember 1929 im dritten Kabinett Švehla und im ersten Kabinett Udržal Eisenbahnminister. Seit 1930 Vorsitzender der Partei: Vgl. PT vom 2.6.1935.

NĚMEC, Antonín (1858-1926), Journalist, ab Ende der neunziger Jahre führender Politiker der tschechischen Sozialdemokraten. 1907-1918 Abgeordneter des Reichsrats, 1918 Stellvertretender Vorsitzender des Tschechoslowakischen Nationalausschusses, 1918-1925 Abgeordneter der Nationalversammlung, ab 1925 Ehrenvorsitzender seiner Partei: Vgl. ČBS, S. 483.

NĚMEC, Václav (1845-1924), Goldschmied und Schmuckhändler. Ab 1881 Mitglied der Prager Kammer, ab 1896 ihr provisorischer, ab 1900 gewählter Präsident. 18891907 Abgeordneter des böhmischen Landtags, 1891/92 Abgeordneter des Wiener Reichsrats: Vgl. BLGBL, Band III, S. 22.

PETERS, Gustav (1885-1959), 1911 zum Dr. phil. promoviert, 1918/19 Beamter der deutschböhmischen Landesregierung, 1920-1926 Leiter der Deutschpolitischen Arbeitsstelle bzw. ihres Nachfolgers, des Deutschpolitischen Arbeitsamtes, bis 1934 auBerdem einer der ständigen sudetendeutschen Vertreter im Verband der deutschen Volksgruppen in Europa. Politische Betätigung ab 1928 als Mitbegründer der Deutschen Arbeits- und Wirtschaftsgemeinschaft (DAWG). 1929 als Mann der Wirtschaft DAWG-Kandidat für die Parlamentswahlen. 1929-1938 Abgeordneter der Nationalversammlung, 1935-38 für die SdP. 1935-38 auch Mitglied der SdP-Hauptleitung: Vgl. Balling, Von Reval bis Bukarest, Band 1, S. 246.

POSPÍSIL, Vilém (1873-1942), seit 1902 Beamter der Prager städtischen Sparkasse, seit 1917 deren Direktor, 1922-1926 ihr Oberdirektor. 1926-1934 Gouverneur der Tschechoslowakischen Staatsbank. Mitglied der Finanzkommission des Völkerbunds, Gründer und erster Vorsitzender des Verbands tschechoslowakischer Sparkassen. Mitarbeiter Rašíns: Vgl. ČBS, S. 564.

PREISS, Jaroslav, geboren 1870, nach dem Besuch des Gymnasiums und dem Jurastudium in Graz, an der Prager Technischen Universität und in Leipzig. Ab 1900 volkswirtschaftlicher Redakteur der „Národní listy“. Hier Vorkämpfer der tschechischen wirtschaftlichen Emanzipation von Wien, besonders Einsatz für die Zentralbank der tschechischen Sparkassen und für die Expansion der Živnostenská banka in die slawischen Gebiete der Monarchie außerhalb Böhmens. Mitbegründer und - seit 1902 Sekretär des Vereins tschechischer Textilindustrieller; gleichzeitig Übernahme der Redaktion des Verbandsorgans „Textilní obzor“. Ab 1904 mit der Redaktion der „Fi- 
nanční listy“ befaßt. Zu dieser Zeit Verdichtung der Beziehungen zur Živnostenská banka. 1907 Eintritt in deren Dienste; Auftrag, eine Hypothekar- und Industrieabteilung aufzubauen. 1910 Stellvertreter des Oberdirektors. Im Juni 1916 als Propagator der Parole „Svi̊j k svému“ (Jeder zu den Seinen), die eine Trennung der Wirtschaft entlang der nationalen Grenzen implizierte, festgenommen und wegen Hochverrats angeklagt. Diese Affäre konnte Preiss' Ruf als Exponent der nationaltschechischen Wirtschaft nur festigen. Nach vierzehnmonatiger Haft amnestiert. Bald Oberdirektor der Živnostenská banka. Als Vorsitzender der größten tschechischen Bank und Lenker ihres umfangreichen Industriekonzerns, als wirtschaftspolitischer Berater der Burg und, ab 1930, auch als Präsident des Zentralverbands unbestritten die zentrale Gestalt im Wirtschaftsleben der Ersten Republik: Vgl. WI 12 (1930), S. $1754 \mathrm{f}$.

PROKU゚PEK, Adolf (1868-1934), Studium der Volkswirtschaft und der Rechtswissenschaft in Prag und Halle/Saale, Übernahme des väterlichen Gutes. 1909 Präsident der tschechischen Sektion des Landeskulturrates für Böhmen; Mitglied des österreichischen Landwirtschaftsrats, 1911-1913 Mitglied des böhmischen Landtags, 19181934 Abgeordneter der Nationalversammlung: Vgl. BLGBL, Band 3, S. 339.

RAŠ́n, Alois (1867-1923), Anwalt, Publizist, Ökonom, Politiker. Nach verschiedenen politischen Aktivitäten 1907 Eintritt in die jungtschechische Partei, 1911 für diese Abgeordneter des Reichsrats. 1910 faktischer Leiter der "Národní listy“. Mit an der Spitze des einheimischen Widerstands. 1916 zusammen mit Kramář wegen Hochverrats zum Tode verurteilt. 1917 amnestiert. Mitglied des Nationalausschusses, maßgeblich beteiligt an der Organisation des Umsturzes. Ab November 1918 Abgeordneter, führendes Mitglied der Nationaldemokraten und deren Vertreter in der Pětka. November 1918 bis Juni 1919 und Oktober 1922 bis zu seinem Tode durch ein Attentat Finanzminister: Vgl. ČBS, S. 586. - Lacina, Rašín.

RAUCHBERG, Heinrich (1860-1938), 1896 bis 1930 Professor für Statistik, Verwaltungslehre, österreichisches Verwaltungsrecht und Völkerrecht an der deutschen Universität Prag: Vgl. BLGBL, Band 3, S. 388.

ROSCHE, Alfred (1884-1947), Sohn eines Kleinhändlers aus Schluckenau. Studium der Rechte in Graz und Prag, Erwerb gründlicher Kenntnisse in Finanzwissenschaft und Statistik. Konzipient, dann Rechtsanwalt und Inhaber eines Nixdorfer Exportbetriebs mit mehr als 300 Arbeitern: Vgl. WI 10 (1928), S. 884.

SCHERB, Friedrich, geboren 1865, Dr. ing., beschäftigt bei den Britannia Kohlenwerken in Seestadtl, dort bald in leitenden Stellungen. 1916 Verwaltungsrat der FalkenauEgerer Bergbaugesellschaft. „Multifunktionär" im Wirtschaftsverbandswesen und in der Politik: Jahrelang Mitglied des Stadtrats sowie der Stadt- und der Bezirksvertretung Eger; 1902 Mitglied der Kammer, 1910 deren provisorischer Vorsitzender, 1918 Präsident. Später auch Mitglied in der Zentrale der Tschechoslowakischen Handelsund Gewerbekammern, im Wirtschaftsbeirat, im Zentraleisenbahnrat, im Verwaltungsausschuß des Exportinstituts, im Handelspreis- sowie im Kohlenbeirat. Im DHI Mitglied des Präsidial-, des Arbeitgeber- und des Finanzausschusses: Vgl. MDHI 16 (1935), S. 186.

SCHICHT, Heinrich, Angehöriger der dritten Generation der von Heinrichs Großvater Georg im Jahre 1848 gegründeten Industriellendynastie Schicht. Georg Schichts Sohn Johann errichtete 1882 in Aussig die Seifenfabrik, die ab 1887 für die Herstellung von verwandten Öl- und Fettprodukten ausgebaut wurde. Das Unternehmen 
verdreifachte allein zwischen 1909 und 1913 seine Umsätze von 30 auf 100 Millionen Goldkronen und expandierte zum Großkonzern, der sich zwischen 1902 und 1922 verschiedene Werke angliederte und 1904 zusätzlich eigene Kohlengruben erwarb. Das Kapital von ursprünglich 10 Millionen Kronen wurde bis 1914 auf 30 Millionen Kronen erhöht. Die Nostrifizierung trennte nach 1918 die Betriebe außerhalb der Tschechoslowakei ab. Die Schicht AG in der ČSR war mit dem Aussiger Stammwerk, den Kohlengruben und der Lobositzer Ölfabrik aber immer noch eines der größten industriellen Konglomerate des neuen Staates. Heinrich, der Sohn Johann Schichts, studierte an den Technischen Hochschulen in Wien und in Berlin. 1903 als Betriebsleiter und Chemiker Eintritt in die väterliche Firma. 1906, anläßlich der Umwandlung des Familienunternehmens in eine Aktiengesellschaft, deren Vizepräsident. 1907, nach dem Tod des Vaters, Übernahme der Präsidentschaft. Als Leiter des Unternehmens auch technologischer Vorreiter: Beispielsweise 1908 Inbetriebnahme der ersten Öl- und Fetthärtungsanlage Europas sowie der ersten Seifengießmaschinen. Im Ersten Weltkrieg Leitung des Kriegsverbandes der Öl- und Fettindustrie und Vorsitz in der Öl- und Fettzentrale. Aufgrund der prominenten Position in der Kriegswirtschaftsverwaltung und der wirtschaftlichen Bedeutung seiner Unternehmen 1918 natürlicher Anwärter auf den Vorsitz des Hauptverbands. Mit der Vereinigung von Zentralverband und DHI 1928 ex officio auch stellvertretender Vorsitzender im Zentralverband. In den späteren zwanziger Jahren Weitung des Aktionsradius über die Tschechoslowakei hinaus durch die Fusion seines Unternehmens mit Unilever. Aufgrund der zeit- und kräftezehrenden, mit häufigen Auslandsreisen verbundenen Leitungstätigkeit in dem internationalen Konzern schon ab 1929 weitgehender Übergang der Geschäftsführung an den Vizepräsidenten Mühlig. 1931 Rückzug aus allen Ämtern in DHI und Zentralverband: Vgl. HR vom 25. 6. 1931, S. 3. - MDHI 9 (1928), S. 57. - WI 7 (1925), S. $370 \mathrm{ff}$.

STRANSKÝ, Adolf (1855-1931), Anwalt und Journalist, seit 1893 Herausgeber der „Lidové Noviny“, um 1900 prominentester Vertreter der mährischen Jungtschechen. 1895-1918 Mitglied des Reichrats und der mährischen Landesversammlung. 19181925 Mitglied der Nationaldemokraten. Mitglied des Nationalausschusses und der Revolutionären Nationalversammlung, im Kabinett Kramár bis Frühjahr 1919 erster Handelsminister der Republik. 1920-1925 Mitglied des Senats. 1925 Gründungsmitglied der Nationalen Partei der Arbeit, nach deren Mißerfolg Abschied von der Politik. Präsident der Prager Eisengesellschaft: Vgl. ČBS, S. 663. - WI 13 (1931), S. $1812 \mathrm{f}$. STŘfBRNÝ, Jiří (1880-1955), Journalist, 1918 Mitglied des Nationalausschusses und Vorkämpfer des Umsturzes. 1918-1928 und 1929-1935 Abgeordneter, 1920-1926 Vizevorsitzender der nationalsozialistischen Partei. Post-, Eisenbahn- und Verteidigungsminister. Im September 1926 aus der Partei ausgeschlossen, später im faschistischen Spektrum angesiedelt. 1934 Vizevorsitzender der Nationalen Vereinigung: Vgl. ČBS, S. 667.

SYROVÝ, Jan (1888-1970), 1927-1933 Generalstabschef, 1933-1938 Generalinspekteur der tschechosiowakischen Armee, 1926 und 1938/39 Verteidigungsminister, September bis Dezember 1938 Regierungschef: Vgl. ČBS, S. 680.

Š́́MAL, Přemysl (1867-1941), enger Mitarbeiter und Vertrauensmann Masaryks, Vorkämpfer des einheimischen Widerstands, Mitglied und - seit 1915 - Führer der „Maffia“. 1918/1919 Überführung der Mehrheit der Mitglieder der Realistenpartei in die 
Tschechoslowakische staatsrechtliche Partei (seit 1919 Nationaldemokraten). Abgeordneter der Revolutionären Nationalversammlung, 1919 Oberbürgermeister von Prag, 1918 bis 1919 Kanzler des Präsidenten der Republik: Vgl. ČBS, S. 684.

TELTSCHER, Rudolf (?-1932), Ingenieur, Teilhaber der Firma Teltscher und Löwy, Reichenberg-Röchlitz-Wien, und Mitbegründer der 1924 aus dieser hervorgegangenen Aktiengesellschaft. Geboren in Wien. Studium an der dortigen Staatsgewerbeschule. Mitarbeit im väterlichen Textilbetrieb, dann Aufbau der Röchlitzer Weberei und Appretur, die sich vor allem durch den Export schnell entwickelte. Umwandlung in eine Aktiengesellschaft unter der Regie der Anglo-Tschechischen Bank. Verwaltungsratsmitglied in diesem Institut. Mitbegründer des ADTV, dessen zweiter Vorsitzender, Vizepräsident der Reichenberger Handels- und Gewerbekammer, Präsident der unter Teltschers Ägide gegründeten Versicherungsgesellschaft „Union“ in Prag, die zum wichtigsten Versicherungsinstitut der deutschen Wirtschaft in der Tschechoslowakei wurde. Seit 1924 auch im Präsidium der Reichenberger Messe: Vgl. WI 13 (1931), S. 893.

WEISSBERGER, Otakar (1864-?). Studium in Prag, ab 1883 tätig in der Wirtschaft als Chemiker. Beruflich bedingte Auslandsaufenthalte in Deutschland und Rußland. Später selbständig. Ab 1891 Gesellschafter der Firma „Bronzovna“ in Holešovice. 1900/1901 Gründung weiterer Unternehmen für Farben und leonische Drähte. Gründungsmitglied der westböhmischen Gruppe des Zentralverbands; Übernahme der Führung nach dem Tode des ersten Präsidenten. Anregung der - 1932 realisierten - Regionalvereinigung der vier west- und südböhmischen Organisationen des Industriellenverbands; deren Vorsitzender. Vizepräsident und - von 1930 bis 1934 - Präsident der Handels- und Gewerbekammer Pilsen. Außerdem Mitglied zahlreicher wirtschaftlicher Vereinigungen: Vgl. OB 16 (1934), S. $28 \mathrm{f}$.

ŽIVANSKÝ, Bohdan, geboren 1876 in Brünn, Dr.jur., nach dem Studium der Rechte an der tschechischen Universität in Prag seit 1901 zunächst Konzeptspraktikant an der k.u.k. statistischen Zentralkommission in Wien. 1902 Berufung an die Prager Kammer; deren Sekretär 1917. 1922 zum Generalsekretär der Kammerzentrale gewählt. Ein „Multifunktionär“, als Wirtschaftspraktiker wie Publizist von großem Einfluß: Sekretär des Verbandes der tschechoslowakischen Handelsmühlen und Generalsekretär der Fachgruppe Mühlenindustrie beim Zentralverband, dort 1932 zum Präsidenten gewählt. Seit 1919 auch Präsident der Allgemeinen Pensionsanstalt in Prag. Korrespondierendes Mitglied des Volkswirtschaftsinstituts der Akademie, Mitglied des Statistischen Staatsrates, Beirat für volkswirtschaftliche Fragen, Vizepräsident der Tschechoslowakischen Statistischen Gesellschaft, der Tschechoslowakischen Volkswirtschaftlichen Gesellschaft uvam. Seit 1900 Beiträger der Wirtschaftsrubrik des ČAS, 1902 bis 1905 Redakteur der Wirtschaftsrubrik des Přehled, 1907 bis 1917 Hauptredakteur der Volkswirtschaftsrubrik der „Národní listy“. Außerdem Chefredakteur des Vẽstník UČSOŽK: Vgl. OB 18 (1936), S. 283. 


\section{Abkürzungen}

AA Auswärtiges Amt

ADAP

Akten zur Deutschen Auswärtigen Politik

ADGB

Allgemeiner Deutscher Gewerkschaftsbund

ADTV

Allgemeiner Deutscher Textilverband

AfS

Archiv für Sozialgeschichte

AKPR Archiv kanceláre prezidenta republiky

(Archiv der Kanzlei des Präsidenten der Republik)

AMZV Archiv ministerstva zahraničních věcí

(Archiv des Ministeriums für Auswärtige Angelegenheiten)

ANB Archiv národní banky (heute: Archiv české národní banky)

(Archiv der Nationalbank) (heute: der Tschechischen Nationalbank)

ANM Archiv Národního muzea

(Archiv des Nationalmuseums)

APČR Archiv Parlamentu České republiky

(Archiv des Parlaments der Tschechischen Republik)

BAA Bundesministerium für Auswärtige Angelegenheiten, Wien

BArch-K Bundesarchiv, Abteilung Koblenz

BArch-B Bundesarchiv, Abteilung Berlin

BayHKT Bayerischer Handelskammertag

BayHStA Bayerisches Hauptstaatsarchiv

BayLT Bayerischer Landtag

BayStMÄWA Bayerisches Staatsministerium des Äußern, für Wirtschaft und Arbeit

BdD Bund der Deutschen

BdL Bund der Landwirte

BLGBL Biographisches Lexikon zur Geschichte der böhmischen Länder

$\mathrm{BO} \quad$ Bohemia

BÖ Die Börse

BVMI Bericht des Verbandes mährischer Industrieller in Brünn

C C Cechoslovák (der Tschechoslowake)

ČBS Československý biografický slovník (Tschechoslowakisches

biographisches Wörterbuch)

ČČH Český časopis historický

ČDD Československé dějiny v datech (Tschechoslowakische Geschichte in

Daten)

ČO Československá obrana (Tschechoslowakische Wehr)

ČS České slovo (Tschechisches Wort)

ČSČH Československý časopis historický

ČSR Československá republika (Tschechoslowakische Republik)

ČsSV Československý statistický věstník (Tschechoslowakische

Statistische Mitteilungen)

DAWG Deutsche Arbeits- und Wirtschaftsgemeinschaft

DCSVP Deutsche Christlich-Soziale Volkspartei 


\begin{tabular}{|c|c|}
\hline DDFP & Deutschdemokratische Freiheitspartei \\
\hline DGWP & Deutsche Gewerbepartei \\
\hline DHI & Deutscher Hauptverband der Industrie in der Tschechoslowakei \\
\hline DIHT & Deutscher Industrie- und Handelstag \\
\hline DNP & Deutsche Nationalpartei \\
\hline $\begin{array}{l}\text { DNSAP } \\
\text { dod. }\end{array}$ & $\begin{array}{l}\text { Deutsche National-Sozialistische Arbeiterpartei } \\
\text { dodatky (Zusätze) }\end{array}$ \\
\hline DPA & Deutschpolitische Arbeitsstelle/Deutschpolitisches Arbeitsamt \\
\hline DSA & Der deutsche Staatsangestellte \\
\hline DSAP & $\begin{array}{l}\text { Deutsche Sozialdemokratische Arbeiterpartei in der } \\
\text { Tschechoslowakischen Republik }\end{array}$ \\
\hline DV & Deutsche Volkswirtschaft \\
\hline ET & Elektrotechna Prag \\
\hline FAE & Fondation Archives Européennes (Archiv des Völkerbundes, Genf) \\
\hline FRUS & Foreign Relations of the United States \\
\hline GG & Geschichte und Gesellschaft \\
\hline GMKdD & Genossenschaftliche Mitteilungen der Kreditanstalt der Deutschen \\
\hline GSOS & $\begin{array}{l}\text { Generální sekretariát obrany státu (Generalsekretariat für } \\
\text { Staatsverteidigung) }\end{array}$ \\
\hline HA & Hospodářský archiv (Wirtschaftsarchiv) \\
\hline $\mathrm{HD} / \mathrm{EC}$ & Hospodářské dējiny/Economic History \\
\hline $\mathrm{HP}$ & Hospodářská politika (Wirtschaftspolitik) \\
\hline HPA & Hospodářský parlament (Wirtschaftsparlament) \\
\hline HR & Hospodářský rozhled (Wirtschaftsrundschau) \\
\hline $\mathrm{HŘ}$ & Hraničáŕ (Grenzer) \\
\hline HSR & Historical Social Research \\
\hline HStA & Hauptstaatsarchiv \\
\hline Hక̆ & Hlavní štáb (Generalstab) \\
\hline $\mathrm{HZ}$ & Historische Zeitschrift \\
\hline IfZ & Institut für Zeitgeschichte \\
\hline IHK & Industrie- und Handelskammer \\
\hline IHK-MO & $\begin{array}{l}\text { Industrie- und Handelskammer - Wirtschaftsarchiv München } \\
\text { Oberbayern }\end{array}$ \\
\hline $\mathrm{KdP}$ & Karpatendeutsche Partei \\
\hline KPR & $\begin{array}{l}\text { Kancelář prezidenta republiky } \\
\text { (Kanzlei des Präsidenten der Republik) }\end{array}$ \\
\hline $\mathrm{KZ}$ & Kreuz-Zeitung \\
\hline LNN & Leipziger Neueste Nachrichten \\
\hline MADTV & Mitteilungen des Allgemeinen Deutschen Textilverbandes \\
\hline MD & Ministerstvo dopravy (Verkehrsministerium) \\
\hline MDHI & Mitteilungen des Deutschen Hauptverbandes der Industrie \\
\hline MF & Ministerstvo financí (Ministerium der Finanzen) \\
\hline MF-P & $\begin{array}{l}\text { Ministerstvo financí - presidium (Ministerium der Finanzen - Präsi- } \\
\text { dium) }\end{array}$ \\
\hline & Münchener Neueste Nachrichten \\
\hline & Ministerstvo národní obrany (Ministerium für nationale Verteidigung) \\
\hline
\end{tabular}


MPaT Ministerstvo pošt a telegrafư (Ministerium für Post- und

Telegrafenwesen)

MPOŽ Ministerstvo prưmyslu, obchodu a živností (Ministerium für Industrie, Handel und Gewerbe)

MpSZaOS Ministerstvo pro sjednocení zákonů a organisace státní správy

(Ministerium für die Vereinheitlichung der Gesetze und der

Organisation der Staatsverwaltung)

MpZL Ministerstvo pro zásobování lidu (Ministerium für Volksernährung)

MS

Ministerstvo spravedlnosti (Ministerium der Justiz)

MSDHI Mitteilungen des Sudetendeutschen Hauptverbandes der Industrie

MSOS Meziministerský sbor pro obranu státu (Interministerieller Ausschuß für Staatsverteidigung)

MSP Ministerstvo sociální péče (Ministerium für soziale Fürsorge)

MŠaNO Ministerstvo školství a národní osvěty (Ministerium für Schulwesen und Volkskultur)

MŠaNO- Ministerstvo školství a národní osvěty - presidium (Ministerium für

Schulwesen und Volkskultur- Präsidium)

MU Ministerstvo unifikací (Ministerium für Unifizierung)

MV Ministerstvo vnitra (Ministerium des Innern)

MVDTR Mitteilungen des Verbandes der Deutschböhmischen Textilindustriellen in Reichenberg und des Mährisch-schlesischen Verbandes deutscher

Textilindustrieller in Jägerndorf

MV-P Ministerstvo vnitra - presidium (Ministerium des Innern - Präsidium)

MVP Ministerstvo veřejných prací (Ministerium für öffentliche Arbeiten)

MV-SR Ministerstvo vnitra - stará registratura (Ministerium des Innern - alte

Registratur)

MZ Ministerstvo zemědělství (Ministerium für Landwirtschaft)

MZV Ministerstvo zahraničních věcí (Ministerium für Auswärtige

Angelegenheiten)

MŽ Ministerstvo železnic (Eisenbahnministerium)

NA National Archives, Washington

Nál Národní listy (Nationale Blätter)

NáM Národní muzeum (Nationalmuseum)

NáP Národní politika (Nationale Politik)

ND Naše doba (Unsere Zeit)

NG Nürnberger Prozesse

$\mathrm{NH} \quad$ Naše hranice (Unsere Grenze)

NJP Národní jednota pošumavská (Volkstumsverein für den Böhmerwald)

NJS Národní jednota severočeská (Volkstumsverein für Nordböhmen)

NL Nachlaß

NM Naše menšiny (Unsere Minderheiten)

NO Národnostní obzor (Nationalitäten-Rundschau)

NP Národohospodářský přehled (Volkswirtschaftliche Umschau)

NRČ Národní rada česka/československá (Tschechischer/

Tschechoslowakischer Nationalrat)

NS Národní shromáždění (Nationalversammlung) 
NSBO Nationalsozialistische Betriebszellenorganisation

NSČDDR Národní shromáždění republiky Československé v druhém desítiletí (die Tschechoslowakische Nationalversammlung im zweiten Jahrzehnt der Republik)

NSČPDR Národní shromáždění republiky Československé v prvém desítiletí republiky (die Tschechoslowakische Nationalversammlung im ersten Jahrzehnt der Republik)

NSČPRR Národní shromáždění Československé $\mathrm{v}$ prvním roce republiky (die Tschechoslowakische Nationalversammlung im ersten Jahr der Republik)

NüP Nürnberger Protokolle

OB Observer

ÖStA Österreichisches Staatsarchiv

OEVW Der Osteuropäische Volkswirt

o.J. ohne Jahr

ONH Obzor národohospodářský (Volkswirtschaftliche Rundschau)

o.O. ohne Ort

o.S. ohne Signatur

o.V. ohne Verfasser

OVW Der Ost-Volkswirt

OŽK Obchodní a živnostenská komora (Handels- und Gewerbekammer)

ÖZG Österreichische Zeitschrift für Geschichtswissenschaft

PA Politisches Archiv des Auswärtigen Amtes, Bonn

PMR Předsednictvo ministerské rady (Präsidium des Ministerrats)

PP Prager Presse

PŘ Přítomnost (Gegenwart)

PSGHA Protokolle der Sitzungen des gewerbe- und handelspolitischen Ausschusses

PSOH Poradní sbor pro otázky hospodářské (Beirat für Wirtschaftsfragen)

PSSA Protokolle der Sitzungen des sozialpolitischen Ausschusses

PT Prager Tagblatt

RdI Reichsverband der deutschen Industrie

RGBl Reichsgesetzblatt

RMA Reichsarbeitsministerium

RMEL Reichsministerium für Ernährung und Landwirtschaft

RMFin Reichsfinanzministerium

RMInn Reichsinnenministerium

RMP Reichspostministerium

RMV Reichsministerium für Verkehr

RMWEV Reichsministerium für Wissenschaft, Erziehung und Volksbildung

RMWi Reichswirtschaftsministerium

RNS Revoluční národní shromáždění (Revolutionäre Nationalversammlung)

S. Seite

SB Sborník historický

sb. z. a n. sbírka zákonů a nařízení (Sammmlung der Gesetze und Verordnungen)

$\mathrm{SCHHV}$ Spolek pro chemickou a hutní vyrobu (Verein für chemische und metallurgische Produktion) 
SDHI Sudetendeutscher Hauptverband der Industrie

SdP

$\mathrm{SHB}$

Slg.

SNJM

SNZ

Sp.

SSB

StVG

SÚA

SÚS

TA

TEPAS

TR

TTZPS

TTZRNS

TTZS

TZPS

TZRNS

TZS

UF

ÚM ̌

undat.

ungez.

ÚOŽK

ÚSČP

VB

VDA

VdDSv

$\mathrm{VdS}$

VfZ

VHA

VKPR

der Republik) Staates

Spalte

Tribuna

undatiert

ungezeichnet

\section{der Republik)}

\section{Sudetendeutsche Partei}

Sudetendeutscher Heimatbund

Sammlung der Gesetze und Verordnungen des čechoslovakischen

Svaz národních jednot a matic (Dachverband der Volkstumsvereine)

Svaz německých zemědělců

Slezský sborník

Staatsverteidigungsgesetz

Státní ústřední archiv (Staatliches Zentralarchiv)

Státní úřad statistický (Statistisches Staatsamt)

Technický průmysl, a.s.

Textilrundschau. Mitteilungen des Allgemeinen Deutschen

Textilverbandes

Tisky k těsnopiseckým zprávám Poslanecké sněmovny (Drucksachen zu den stenografischen Berichten des Abgeordnetenhauses)

Tisky k těsnopiseckým zprávám Revolučního národního shromáždění (Drucksachen zu den stenografischen Berichten der Revolutionären Nationalversammlung)

Tisky k těsnopiseckým zprávám Senátu (Drucksachen zu den stenografischen Berichten des Senats)

Tẽsnopisecké zprávy Poslanecké sněmovny (Stenografische Berichte des Abgeordnetenhauses)

Tẽsnopisecké zprávy Revolučního národního shromáždění

(Stenografische Berichte der Revolutionären Nationalversammlung)

Tẽsnopisecké zprávy Senátu (Stenografische Berichte des Senats)

Ursachen und Folgen

Ústřední matice školská (Zentraler Schulverein)

Ústředna obchodních a živnostenských komor (Zentrale der Handelsund Gewerbekammern)

Ústřední svaz československých průmyslníků (Zentralverband der tschechoslowakischen Industriellen)

Völkischer Beobachter

Verein für das Deutschtum im Ausland

Verband der deutschen Staatsangestellten-Vereinigungen

Verbandsnachrichten der deutschen Selbstverwaltungskörper in der

Tschechoslowakischen Republik

Vierteljahrshefte für Zeitgeschichte

Vojenský historický archiv (Militärhistorisches Archiv)

Vojenská kancelář prezidenta republiky (Militärkanzlei des Präsidenten

Věstník obchodní a živnostenské komory v Plzni (Mitteilungsblatt der 
Handels- und Gewerbekammer Pilsen)

VOSG Verordnungsblatt für die sudetendeutschen Gebiete

VSWG Vierteljahrschrift für Sozial- und Wirtschaftsgeschichte

VÚČSOK Věstník ústředny československých obchodních komor (Mitteilungsblatt der Zentrale der tschechoslowakischen Handelskammern)

VZ Vossische Zeitung

WI Die Wirtschaft

WMÖHP Wirtschaftliche Mitteilungen der österreichischen Handelskammer in Prag

WP Wahlperiode

WR Der Wirtschafts-Ring

WWA Weltwirtschaftliches Archiv

ZAA Zeitschrift für Agrargeschichte und Agrarsoziologie

ZBLG Zeitschrift für bayerische Landesgeschichte

ZfG Zeitschrift für Geschichtswissenschaft

ZfKV Zeitschrift für Kommunalverwaltung

ZfU Zeitschrift für Unternehmensgeschichte

ZPSČV Z $\quad$ protokolů schůzí ..československé vlády (Aus den Protokollen der ... Sitzung der Regierung)

ZStAM Zentrales Staatsarchiv, Merseburg

ZŠR Zemská školní rada (Landesschulrat)

ZT Die Zeit

ZÚ Zemský úřad (Landesbehörde)

ŽB Živnostenská banka (Gewerbebank) 


\section{Register}

Bacher, Franz $\quad 51,54,57,65,79,88,99 \mathrm{f}$, 102, 109, 120, 142, $313 \mathrm{f} ., 320,421$

Baeran, Alois 280

Bárta, Rudolf 34,421

Bartoň, Josef 34

Bartoš 309, 357

Bat'a, Tomáš $31,129,151,161,372$

Baumann 115

Baumgartner, Karl 45, 421

Baxa, Karel 24, 421

Bayer, Anton (Antonín) 201, 238, 421

Bechert, Paul 158, 160

Bečka, Bohdan 242

Benda, František 118, 194 f., 234, 242, 263, 310

Benedikt, Leo 213

Beneš, Edvard 1, 22, 41, 63, 69f., 76, 81, $83,90,92,108,110,117,122,163,289$, 298-301, 303, 320, 322-327, 335, $354 \mathrm{f}$, 361, 366, 370, 374, $382 \mathrm{f}$.

Beneš, Georg 341

Beran, Rudolf $\quad 22,96,142,318 f$., 356, 359

Blumenthal $195 \mathrm{f}$.

Bondy, Léon (?-1923) 62, 183f., 217, 421

Bondy, Léon (1875-1934) 422

Bouček, Václav 285, 422

Bradáč, Bohumír 351 f., 354, 357

Brand, Walter 113, 115

Brass, Hermann 45f., 53 f., 422

Budig, Maximilian 124

Chylik $195 \mathrm{f}$.

Cichorius, Theodor $37 \mathrm{f}$., $44 \mathrm{ff}$., 422

Comenius, Jan Amos 236

Coudenhove, Richard von 137

Czech, Ludwig 335, 343, 353

Černý, Jan 52, 62 f., 70, 77 ff., 281, 286, 310

Č́ížek 357, 362

Darré, Walter 120
David, Josef 359,363

Devcic-Siegwardein, Karl 107, 169

Diviš, Jan 153

Doderer, Richard 44 f., 52, 54, 120, 132, 160,422

Drachovský, Josef $\quad 24,309,356,359,422$

Dres(s)ler 193

Drtina, Prokop 202, 236

Dubický, J. 348

Dudek, Walter 158

Dvořáček, Jan 162, 358

Dyk, Viktor 21, 422

Eisenlohr, Ernst 142, 361, $373 \mathrm{f}$.

Eisner, Paul 317

Eliáš, Alois 357

Engliš, Karel 79, 88f., 105, 125, 138, 288, 422

Enhuber, Emil 119

Epsten 168

Fafl, Zdeněk $109,309,423$

Federer 120

Feierfeil, Wenzel 279

Fernegg, Rudolf $37 \mathrm{f} ., 43,94,107,160$

Fierlinger, Zdeněk 382

Flieder, Robert 383

Frank, Karl Hermann 129, 367

Freißler, Robert $\quad 55,423$

Friedmann 327

Gebsattel $38 \mathrm{f}$.

Gessner, Oswald $339 \mathrm{f}$.

Ginzkey, Willy (Willi) 45f., 53, 63, 104 f., 164, 423

Goldberg, Heinrich $77 \mathrm{f}$.

Goltz, Otto $44 \mathrm{f}$., 325, 423

Grimme 329

Grohmann, Kuno 158

Grossmann, Arnošt 184

Gruber, Josef 254, 286, 423

Gruntzel, Josef 71 
Hacker, Gustav 132

Hajn, Antonín 24, 242, 260, 423

Hanreich, Georg 91

Hartig 105

Hartl 53

Hasse, Gustav 195

Havliček, František 236

Heidler, Ferdinand 71

Heinrich 115

Hejda, Jiří $88 \mathrm{f} ., 179 \mathrm{ff} ., 262$

Held, Heinrich 324

Heller 168

Henlein, Konrad 113ff., 119, 123f., 128, 132, 134 ff., 141, 147f., 152-155, 158, $161,165,169,271,370,373$

Herring-Frankensdorf, Friedrich 158

Herzig, Emma Maria 53

Hibsch, Max 119

Hielle, Karl 158, 160

Himmler, Heinrich 375

Hitler, Adolf $16,112,114,120,122,135$, 162 f., 168, 355, 366, 373, 380, 383

Hlinka, Andrej 24

Hodáč, František 21, 31-34, 49f., 59, 70, 76, 80 ff., 84, 92, 94 ff., 98, 104, 107, $116 \mathrm{ff} ., 191,213,310,314,356,374,423$

Hodža, Milan $24,127,155,157,248$, $267,352,361,364,366,382$

Hödl, Antonín 160, 168

Hönig 115

Hoffmann, Albert 168

Holzhausen 327

Horáček, Cyril $317 \mathrm{f}$.

Horner 152

Horpynka, Otto 91, 324

Hotowetz, Rudolf $34,60,62,75,107$, 180,424

Hrubý, Emil 25, 359

Hus, Jan 236

Jaksch, Wenzel 366

Janovsky, Karl $56,62,66,72,74 f$., 88, $107,124,128 \mathrm{f} ., 135-138,140 \mathrm{f} ., 151$, $158,160,165$

Jareš, Josef 356

Jellinek, Fritz 125
Ježek, František 359,424

Jirásek, Alois 24, 424

Jirsák 249

Jung, Rudolf $91,112,134$

Kafka, Bruno 84

Kahr, Gustav von 293

Kaiser, Leonhard $279 \mathrm{f}$.

Kalfus, Josef 366

Karlík, Hanuš 34, 424

Kaspar, Rudolf 112,132

Kerner 40

Keynes, John M. 130

Kiesewetter, Anton 115, 119, $164 \mathrm{f}$.

Kirchhof, Carl (Karel) 219, 256, 424

Kislinger, Josef $\quad 45,53-56,63,81-84,87$, 89,94 f., $99,104,107,110,120,123,160$, $163 \mathrm{ff} ., 171,265$

Klaubert, Hermann 158

Klecanda 356

Klofáč, Václav 22, 24, 359

Kluge, Franz 158, 160

Kneisl 151

Knirsch, Hans 112

Knoll 151

Koch, Walter 120, 298, 300f., 307, 311, 325,335

Köllner, Fritz 115, 124, 146, 364

Koloušek, Jan 56

Kostka, Karl 120, 145

Kotrba, Milton 94

Kovářik, František 424

Kramáŕ, Karel $21,24,28,41,57,71,83$, 92, 295, 369

Krebs, Hans 112, 137

Kreibich, Emil 135, 158, 164

Krejčí, František Václav 24, 425

Krofta, Kamil 327, 373 f., 382

Kř́žik, František 318

Kubelka 55

Küster 220

Kuffner, Hanuš 369

Kundt, Ernst $119,154,161,171$

Kwiatkowski, 104 
Larisch, Hermann $\quad 46,158$

Lasalle, Ferdinand 236

Ledebur-Wicheln, Eugen $53 \mathrm{f}$., 84

Lehmann, Wilhelm 297

Levit 203

Liebieg, Gisbert 103

Liebieg, Theodor 34, $45 \mathrm{f}$., 53, $63 \mathrm{ff} ., 100$, $103,105,125,155,157$ ff., 161-165, 168f., 220, 262, 265, 396, 425

Liebieg, Wolfgang 164

Lindeiner-Wildau, Hans Erdmann von 322

Lodgman, Rudolf von $38,42,52 \mathrm{ff}$., $58 \mathrm{f}$., $63,79,81,182$

Löw-Beer, Alfred 190, 193

Loewenstein, Karel 104

Lüdinghausen, Freiherr von 164

Lukavský, František 200, 202

Luksch 110

Luschka, Felix 102, 351

Machník, František 351, 353f., 357, 360, 363, 379

Mahlmann, Freddy 164

Malinský, František 33 f., 50, 59, 82, $183 \mathrm{f}$., 425

Malypetr, Jan 177

Marek, Karl 108ff., 122f., 311, 355, $382 \mathrm{ff}$.

Marty, Jan 254

Marx, Karl 236

Mařík, Bohuslav 34, 82, 426

Masaryk, Tomáš Garrigue $21,38,40,53$, $59,63,69,83,90,92,121,163,203,235$, 285, 317, 366, 373

Masaryková, Alice 24, 84

Mastný, Vojtech 373

Matoušek, Josef 117, 194, 242, 309

Mayer, Robert 107, 180f., 189

Mayr-Harting, Robert 53, 63, 84, 90 , 102, 214, 253

Medinger, Wilhelm 51, $53 \mathrm{f}$., $59 \mathrm{f}$., $63 \mathrm{f}$., 66, 68, $71 \mathrm{f} ., 102,105,283 \mathrm{f} ., 426$

Mixa 94, 110, 118, 127, 249, 265

Mlčoch, Rudolf $161 \mathrm{f} ., 177,181,242$, 244, 249
Mühlig, Joseph (Josef) Max $44 \mathrm{f}$., $51 \mathrm{f}$., 103, 106 f., $109 \mathrm{f} ., 115,120 \mathrm{f} ., 125,155-$ 161,426

Najman, Josef $177,206,247 \mathrm{f}$, 427

Naumann, Friedrich 40

Nekvasil $280 f$.

Němec, Antonín 24, 427

Němec, Václav 184, 216f., 427

Němec 357

Neumann 357

Neurath, Konstantin von 373

Neuwirth, Hans 362

Novák, Ladislav $33,87,89,91,94,98$, $104 \mathrm{f} ., 217,242,306$

Oberleithner 80

Pavel, Antonín 356

Pavlü, Bohdan 382

Pechmann 200, $204 \mathrm{ff}$.

Pekárek, Jan 359

Peroutka, Ferdinand 202, 310

Peschka, Ernst 124

Peters, Gustav 54ff., 135, 179, 363f., 427

Petr, Heinrich $189,190-193,238,334$

Petrovický 242

Petschek 295, 372

Pfeiffer, Anton 220

Pflock 324, $334 \mathrm{f}$.

Philippovich, Eugen von 40

Pimper, Antonín $88 \mathrm{f}$.

Podhajský, Alois 356

Pokorný, Matýs 201f., 236

Pospísiil, Vilém 24, 356, 427

Preiss, Jaroslav 21, 33f., 70, 73, 76, 82, 84, $87 \mathrm{ff}$., $95 \mathrm{f}$., 100, 102-106, 110, $115 \mathrm{ff} ., 120-123,126,156 \mathrm{ff}$., 161-164, $167 f ., 177,283,288,310,357,427$

Prokop 34

Prokůpek, Adolf 24, 428

Rašín, Alois $28,39,79,85,295,319,428$

Ratshesky $104 \mathrm{f}$.

Rauchberg, Heinrich $315,317,428$

Reifenstuhl, Friedrich 209

Reinl, Heinrich 121 
Richter, Felix 160

Richter, Max 169

Richter, Max von $164 \mathrm{f}$.

Richter, Wolfgang 124, 135, 157f., 162, 165,169

Richter 164

Riedel, Arbo 164

Riedel, Walter 150, 158, 160, $164 \mathrm{f}$.

Riedl 105

Riethof, Oskar 107, 158

Rohan, Fürst 164

Roos, Emil 356

Rosche, Alfred 91, 109, $118 \mathrm{ff} ., 124,135$, 428

Roskošný, Jan 34

Rutha, Heinz 354

Řehák 242

Saenger, Samuel $\quad 43,74$

Samek, František 179, 183 f., 186, 242 ff., $259 f$.

Samek, Jan 34

Schälzky 290

Schauer, Antonín 24, 356

Scherb, Friedrich 107, 209, 211, $213 \mathrm{ff}$., 217, 238, 428

Schicht, Georg 153

Schicht, Heinrich 44 f., 54, 62, 64, 82, 85, $94 \mathrm{f}$., $99 \mathrm{f}$., $102 \mathrm{f}$., $106 \mathrm{f}$., 120, 153, 295, 309,428

Schicht, Kurt 153

Schicht, Werner 153

Schicketanz, Rudolf 144

Schmidt, Reinhard 158

Schubert, Leo 112, 323

Schuster, Václav 71, 73, 84, 183, 238

Sebekovsky, Wilhelm 119

Siegl 54

Simm 150

Singer 119

Sonnenschein 65, 81, 93

Soukup, František 24

Spann, Otmar 113

Spina, Franz 84, 90, 114f., 319, 353, 366

Spiro 168

Spittaler 119
Stade, Ernst $\quad 158,162,170$

Steinecke, Adolf 158

Stern, Gustav $317 \mathrm{f}$.

Stoupal 120, 195

Stranský, Adolf $24,50,57,60 f ., 65,189$, 429

Stresemann, Gustav 90, 322

Střibrný, Jiří 22, 24, 429

Suchý 362

Svěcený 356

Svoboda, Karel 236, 356

Sýkora, Artuš 356

Syrový, Jan 357, 429

Sádek 164, 168

Sámal, Přemysl 24, 53, $63 \mathrm{f} ., 83 \mathrm{f}$., 96, $102,104 f ., 122,153,163,283,357,359$, 429

Šedý 194,196

Simek 193

Škarda, Eugen 34

Spaček 242

Srámek, Jan 327

Šrobáŕ, Vavro 24, $175 \mathrm{f}$.

Stangler 69

Švehla, Antonín $22,24,85,241,295,310 f$.

Taub, Siegfried 145,353

Teltscher, Rudolf $45 \mathrm{f}$., 62, $64 \mathrm{ff} ., 80,100$, 430

Tichi, Hans $160,193,228$

Trautmannsdorff, Grafen von 373

Třebický, Jan 116, 238, 265

Tschakert, Robert 128

Tugendhat, Hans 44, 107

Tusar 24, 57, 71, 297, 300, 317

Tvrzník, Julius 247

Udržal, František $\quad 22,24,102,108,310$

Ulbrich 55

Ulrich, František 254, 256

Vansittart, Robert G. 370

Viškovský, Alois 34, 36, 39, 59

Vogl, Karel 34

Votruba 242 
Wällner, Emil 323

Waldes 183

Wannenmacher, Rudolf 169

Weber, Wilhelm (Willy; Vilém) 123, 158, 160

Weden, Moritz 122

Weil, Friedrich $\quad 64,88$

Weissberger, Otakar 116, 179, $196 \mathrm{ff}$., $201 \mathrm{ff} ., 430$

Wien-Claudi, Franz 54

Winter, Hermann 152

Winternitz, Josef 312
Wolf, Hans 119

Wolf-Zdekauer $185,187 \mathrm{f}$.

Wolfrum, Hermann 158

Wollner, Georg 131

Wulle 305

Zajicek, Erwin 374

Zebisch 44, 107

Zierhut, Wolfgang 206, 228

Živanský, Bohdan $184,235,240,249$, 256,430 